Review

\title{
Green Transition: The Frontier of the Digicircular Economy Evidenced from a Systematic Literature Review
}

\author{
Fabio De Felice $^{1}$ (D) and Antonella Petrillo ${ }^{2, *(D)}$ \\ 1 Dipartimento di Ingegneria Civile e Meccanica, Università degli Studi di Cassino e del Lazio Meridionale, \\ 03043 Cassino, FR, Italy; defelice@unicas.it \\ 2 Dipartimento di Ingegneria, Università degli Studi di Napoli Parthenope, 80143 Napoli, NA, Italy \\ * Correspondence: antonella.petrillo@uniparthenope.it; Tel.: +39-0815476747
}

check for

updates

Citation: De Felice, F.; Petrillo, A. Green Transition: The Frontier of the Digicircular Economy Evidenced from a Systematic Literature Review. Sustainability 2021, 13, 11068. https: / / doi.org/10.3390/su131911068

Academic Editors:

Gianmarco Bressanelli,

Federico Adrodegari, Daniela

Cristina Antelmi Pigosso and Vinit Prida

Received: 31 August 2021

Accepted: 4 October 2021

Published: 7 October 2021

Publisher's Note: MDPI stays neutral with regard to jurisdictional claims in published maps and institutional affiliations.

Copyright: (c) 2021 by the authors. Licensee MDPI, Basel, Switzerland. This article is an open access article distributed under the terms and conditions of the Creative Commons Attribution (CC BY) license (https:/ / creativecommons.org/licenses/by/ $4.0 /)$.

\begin{abstract}
Today, the issue of economic circularity is certainly not a new concept. It represents an essential issue in any production system since it is an alternative to the current production and consumption model. The importance of the topic is confirmed worldwide. However, there is still a "circularity gap" that can be bridged in the short and medium term, probably with the use of innovative and digital technologies. In fact, many researchers agree that the sustainable future can be achieved in the long term thanks to digital technologies (i.e., IoT, artificial intelligence, quantum computing etc.) which, thanks to their speed of calculation, are able to identify the right solutions at the right time. The challenge, therefore, will be to develop innovative technologies and tools for the efficient use of resources in industries for sustainable production. Thus, the aim of this study is to define the current state of the art and future research developments in this very promising field. To achieve this goal, the integration of a "set" of tools, based on the AHP method and the PRISMA protocol, is proposed. The results aim to be a guideline for decision makers and researchers interested in this topic.
\end{abstract}

Keywords: circular economy; digital age; technologies; business models; AHP; PRISMA

\section{Introduction}

\subsection{Circular Economy in the Digital Age}

Digitalization is an enabling factor for the transition to a circular economy. In fact, already today's technologies such as artificial intelligence, Internet of Things, big data, and blockchain are the "enablers" of different production processes to improve the use of natural resources and optimize designs, production, and repair and recycling phases of certain products [1,2]. This means that digitalization can strengthen and improve different segments of the circular economy. However, digitalization alone will not automatically lead to greater principles of sustainability. Political tools and strategies are needed to promote digitalization and innovation to manage complex sustainability problems. One of the main critical issues is the unavailability of data [3]. From this perspective, the European Council finally and only recently adopted a regulation confirming EuroHPC (European high performance computing) for the development in Europe of the next generation of supercomputers. The Luxembourg-based EuroHPC Joint Undertaking was created in October 2018 with the aim of "developing, implementing, extending and maintaining a federated, secure and hyper-connected supercomputing and quantum computing ecosystem in the EU", as well as global data services and infrastructures. It is important to highlight a fundamental principle of the regulation, which adds to the doctrine of digital sovereignty. The fundamental principle should be to ensure a green technology solution of the supercomputing platform in line with the EU's green transition goals. In fact, the current energy equation of supercomputing, which generates extremely high computing power in localized points, but absorbs an equally large amount of energy, will be deeply revised in EuroHPC projects. As shown in Figure 1, eight sites were selected for supercomputing centers located in eight 
different EU Member States that will host the new high-performance computing machines. The hosting sites will be located in Sofia (Bulgaria), Ostrava (Czech Republic), Kajaani (Finland), Bologna (Italy), Bissen (Luxembourg), Minho (Portugal), Maribor (Slovenia), and Barcelona (Spain).
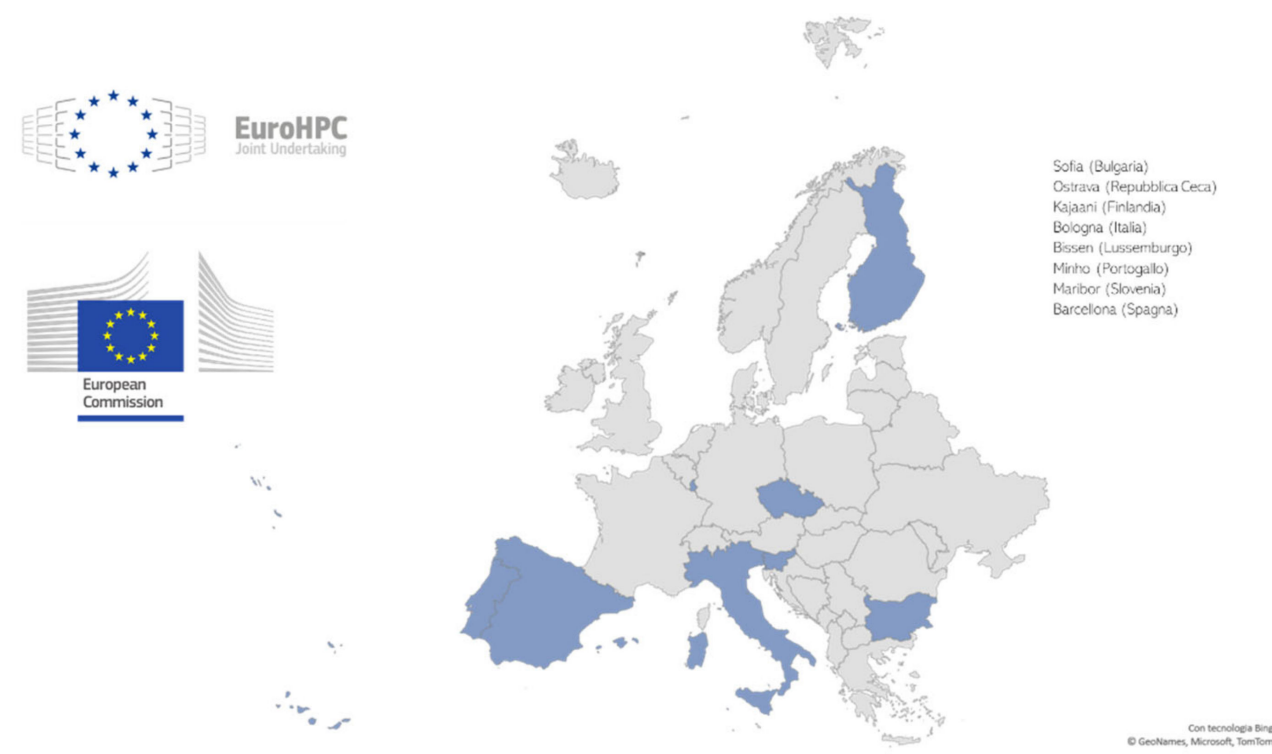

Figure 1. EuroHPC hosting sites.

European policy confirms the awareness that decisive technological discoveries can be useful in the field of sustainability.

\subsection{Motivation of the Research}

Sustainability, understood as environmental, economic, and social sustainability, is a complex system based on an inferential logic [4]. To manage the complexity that comes from sustainability, we need an economic-social-political "system" to handle this complexity. So, if we really want to create a sustainable system, we need to use a "tool" that supports it. In this regard, innovation and digitalization are becoming a priority to drive the transformation of a linear to circular economy. Therefore, many continents and nations have developed indicators to monitor and to measure the growth of innovation and the circular economy at the national level [5]. For example, in Europe, the eco-innovation index is used. Its purpose it to analyze five dimensions: eco-innovation inputs, eco-innovation activities, eco-innovation outputs, resource efficiency and socio-economic outcomes. If, from our point of view, we consider the Italian situation, it emerges that Italy is in tenth position among the EU28 Members, classified as average Eco-I performers. In addition, it is possible to analyze the country profiles to better understand the trends at a European level (Figure 2).

For a better understanding of all the indicators that are monitored, Figure 3 shows the comparison among three typical countries: Luxembourg (reaching 1st place), Italy (as 8th), and Bulgaria (last of the 28 member countries). 


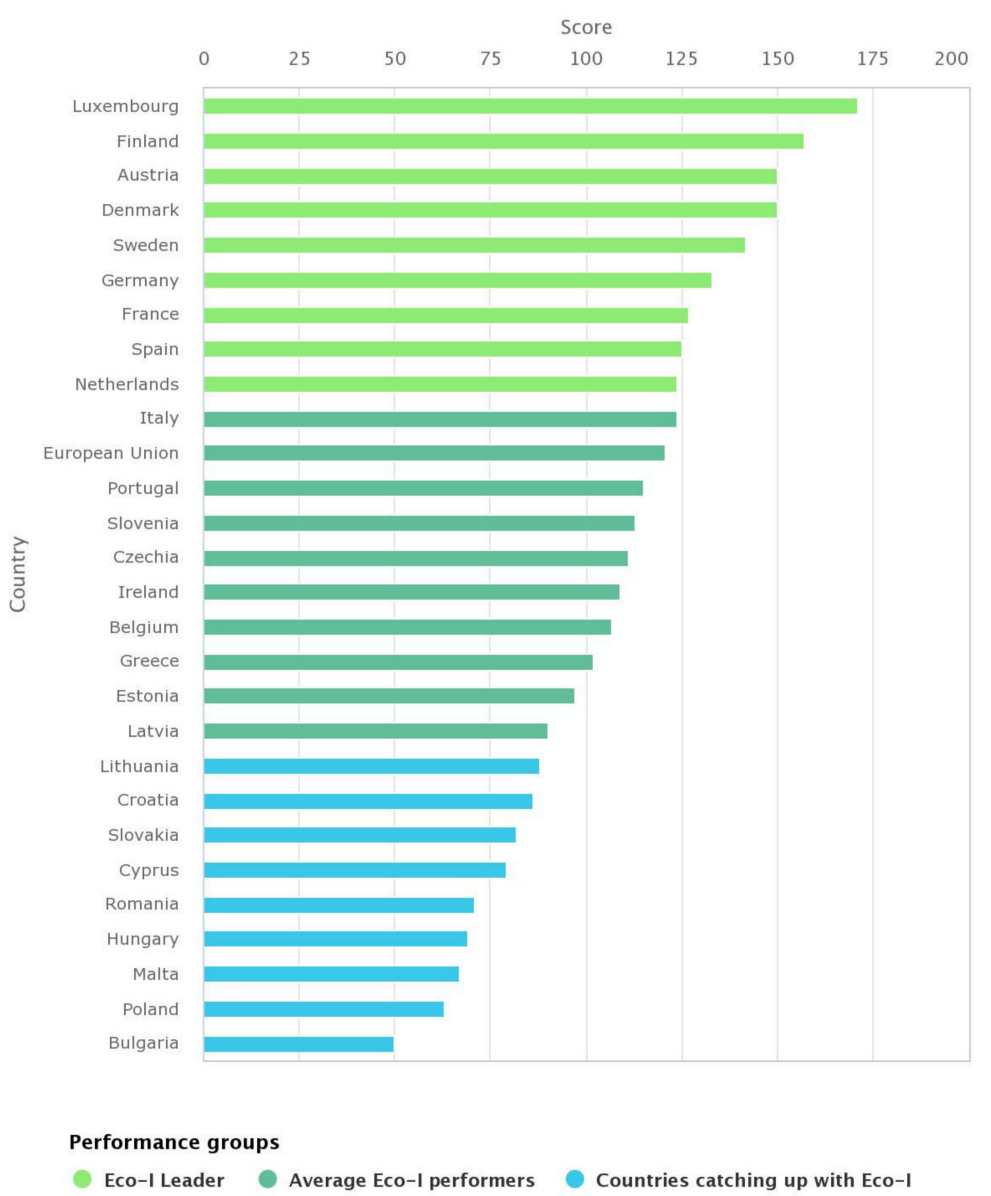

Figure 2. Eco-Innovation Index 2021 (Source: European Union-https: / /ec.europa.eu/environment/ ecoap/indicators/index_en; accessed on 31 August 2021).

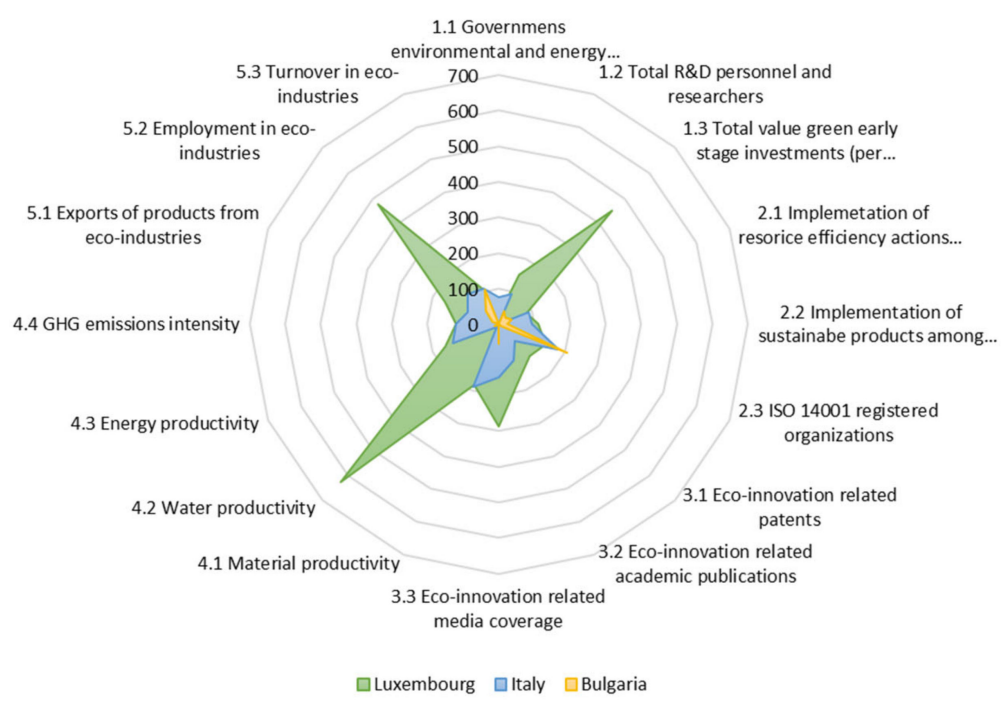

Figure 3. Country Profiles-Eco-Innovation Index 2021 (Authors' elaboration from data provided by European Union-https:/ / ec.europa.eu/environment/ecoap/country_profiles_en; accessed on 31 August 2021).

\subsection{Aim and Structure of the Research}

Nowadays, in our opinion, there is no point in asking whether technology is good or bad. Instead, we must understand how technology is functional to the needs of mankind. Thus, the aim of this study is to investigate if digital technologies might be useful to achieve 
the principles of a circular economy. How are new technologies applied? What are the main areas of application? The research aims to answer these questions. The results aim to identify existing gaps. In addition, the findings aim to be a guide for policy makers and researchers to define strategic choices and future studies.

The rest of the paper is organized as follows. Section 2 outlines the rationale of the research and the context of the analysis. In Section 3 the methodological approach is explained. In Section 4 the main results are summarized. Section 5 points out the empirical evidence and main challenges that emerged from the analysis. Finally, Section 6 summarizes the main conclusions of the study.

\section{Rationale}

The main objective of this study is to explore the theme of the circular economy in the digital age. Achieving this goal is not easy. It is a complex problem. In the management of complex problems, it is necessary to use tools that allow to solve problems quickly, often having little information available. Based on this consideration we decided to develop a systematic literature review (SLR). In fact, systematic reviews are increasingly numerous and widely used for the definition of management/policy decisions and strategies [6]. A SLR aims to provide a transparent and complete report on a types of research (i.e., clinical studies, social studies, etc.). Given the importance of identifying high quality systematic reviews, numerous tools have been proposed (i.e., PRISMA, AMSTAR 2, etc.), but only a few of them allow to conduct an adequate critical evaluation. In the present study, the PRISMA protocol (preferred reporting items for systematic reviews and meta-analyses) is applied [7]. PRISMA is a guideline and an essential tool for conducting systematic reviews. It helps researchers in the process of drafting a survey, underlining its essential aspects. It can be used to perform a critical analysis of reviews already published. The items of the PRISMA protocol provide for indicating: eligibility criteria for articles; the sources of information database and time period of search execution; how the studies were selected; how the data from the individual studies were extracted; and a summary of the results. Finally, an integral part of the protocol is the discussion of the results and any limitations. A very important assumption from our point of view is that the definition of an effective search strategy is essential to conduct a good literature analysis [8]. Typical questions underlying a literature review are, for example, how to define the research questions; how to define the search terms; and how the results obtained should help to precisely outline the contribution of current research. However, these questions are often not well reasoned and justified. In general, the reader must accept them. Furthermore, a SLR could be influenced by numerous biases, increasingly include non-randomized studies. The quantity of articles and their heterogeneity can be confusing and disorienting. For this reason, the present study is focused on integrating the traditional PRISMA protocol with a multi-criteria approach based on analytic hierarchy process (AHP). Otherwise, in our opinion, the risk could be that of delineating a generic framework not useful from a practical and managerial point of view. In addition, it should be noted that in the field of engineering systematic literature review is an approach recently implemented, unlike traditional sectors where they are well established. Thus, this study is performed using a "set" of tools to avoid obtaining "unattractive", not significant, and too general results already analyzed in the literature. Therefore, we intend to propose a method to have a more objective evaluation of the information available than the traditional revisions.

With this premise we have developed the Analytical-PRISMA (A-PRISMA) methodological approach proposed in the present study. More details are provided and explained in the following sections. In particular, in Section 3 a description of theoretical basis of AHP technique is provided. In addition, the integration of AHP and PRISMA, the A-PRISMA approach, is described to allow readers to replicate and build it. 


\section{Materials and Methods}

\subsection{Analytic Hierarchy Process (AHP) Method}

AHP is a multi-criteria decision support technique developed in the 1970s by naturalized Iraqi American mathematician Prof. Thomas L. Saaty [9]. AHP allows experts to compare multiple alternatives in relation to a plurality of criteria, either quantitative or qualitative. Briefly, the meaning of AHP can be summarized as follows [10]:

- 'Analytic' or decompose the problem into its elementary components

- 'Hierarchy' or design the decision problem in a hierarchy defining the goal, criteria and the sub-criteria

- 'Process' the data and evaluations in order to achieve the final result

Thus, from a methodological point of view, the following steps are carried out. Firstly, the experts team define the decision hierarchy. Secondly, the experts team express judgments on pairs of elements with respect to a controlling element in order to derive ratio scales that then are synthesized throughout the structure used to select the best alternative. The elements are compared in pairs by assigning a relative importance score to the other according to the Saaty's semantic scale (from 1 to 9 with increasing values of importance). For a general AHP applications, we can consider that $A_{1}, A_{2}, \ldots, A_{m}$ denote a set of elements, while $a_{i j}$ represents a quantified judgment on a pair of $A_{i}, A j$. Through the pairwise comparisons, an $[\mathrm{m} \times \mathrm{m}]$ matrix $\mathrm{A}$ is built as follows:

\begin{tabular}{|c|c|c|c|c|c|}
\hline \multirow{5}{*}{$\mathrm{A}=\mathrm{a}_{\mathrm{ij}}=$} & & $\mathrm{A}_{1}$ & $\mathrm{~A}_{2}$ & $\ldots$ & $\mathrm{A}_{\mathrm{m}}$ \\
\hline & $\mathrm{A}_{1}$ & 1 & $a_{12}$ & $\ldots$ & $\mathrm{a}_{1 \mathrm{~m}}$ \\
\hline & $\mathrm{A}_{2}$ & $1 / a_{12}$ & 1 & $\ldots$ & $\mathrm{a}_{2 \mathrm{~m}}$ \\
\hline & $\ldots$ & $\ldots$ & $\ldots$ & $\ldots$ & \\
\hline & $A_{m}$ & $1 / \mathrm{a}_{1 \mathrm{~m}}$ & $1 / a_{2 m}$ & $\ldots$ & 1 \\
\hline
\end{tabular}

A is a positive reciprocal matrix. The result of the comparison is the so-called dominance coefficient, $\mathrm{a}_{\mathrm{ij}}$, that represents the relative importance of the component on row (i) over the component on column (j), i.e., $\mathrm{a}_{\mathrm{ij}}=w_{i} / w_{j}$. If $\mathrm{A}$ is a consistency matrix, the relationships between weights $w_{\mathrm{i}}, \mathrm{w}_{\mathrm{j}}$ and judgments $\mathrm{a}_{\mathrm{ij}}$ are simply given by $\mathrm{a}_{\mathrm{ij}}=w_{\mathrm{i}} / w_{\mathrm{j}}$ (for $i, j=1,2, \ldots, m)$ and:

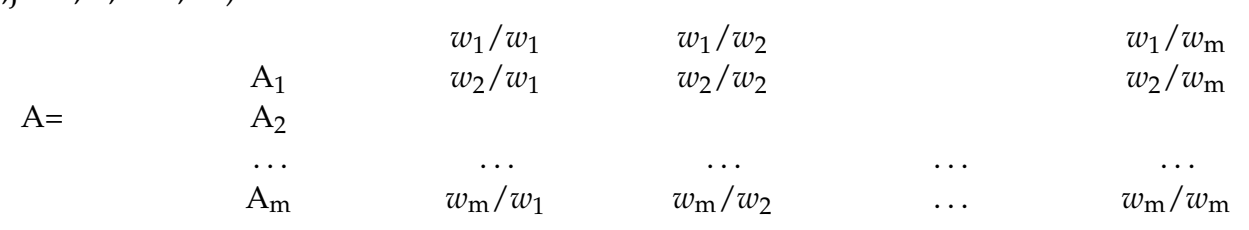

If matrix $w$ is a non-zero vector, there is a $\lambda_{\max }$ of $\mathrm{A} w=\lambda_{\max } w$, which is the largest eigenvalue of matrix A. After all, pairwise comparisons are completed, the priority weight vector $(w)$ is computed as the unique solution of $A w=\lambda_{\max } w$, where $\lambda_{\max }$ is the largest eigenvalue of matrix A. Finally, a consistency index is estimated. Saaty proposed the consistency index (CI) to verify the consistency of the comparison matrix. The consistency index can be calculated by: $\mathrm{CI}=\left(\lambda_{\max }-\mathrm{n}\right) / \mathrm{n}-1$. In general, if $\mathrm{CI}$ is less than 0.10 , the judgments can be deemed to be satisfactory. It has been scientifically demonstrated that in the case of perfect consistency of judgments, the matrix of comparisons that is formed has particular properties: it is symmetrical, reciprocal, and consistent.

\subsection{Analytical-PRISMA (A-PRISMA) Approach}

The proposed procedure is based on the assumption of applying a multi-criteria decision-making approach as a basis for a systematic literature review. Figure 4 aims to summarize the main logical steps of the methodological approach A-PRISMA. As highlighted, a focal point is the definition of an experts team with the aim of identifying the research questions (RQ) and search criteria (SC) in order to select the documents to be investigated for literature analysis. An AHP decision model was designed and built by the experts team for the definition of search criteria (SC) in order to support their identification in a rigorous and scientific way. Obviously, the principles established by the PRISMA 
protocol were taken into consideration for the definition of the final list of documents to be analyzed. More details on A-PRISMA modeling are provided in Section 3.3.

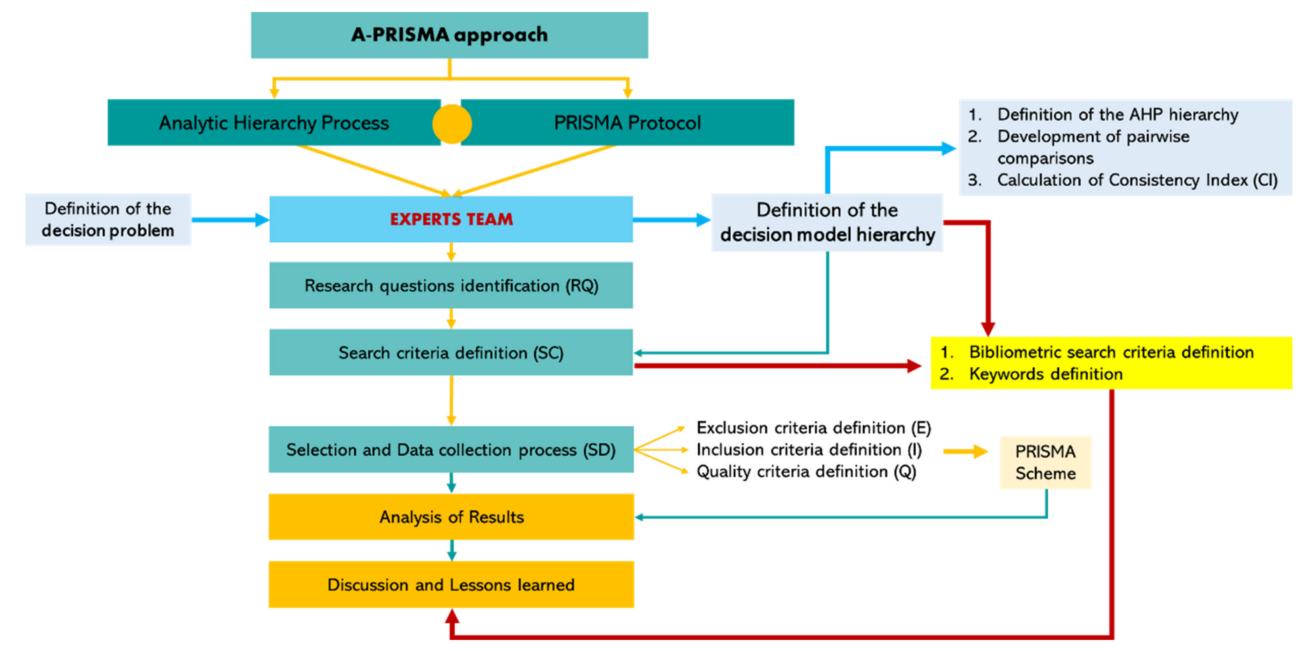

Figure 4. Framework of A-PRISMA approach.

\subsection{A-PRISMA Modeling}

In order to develop a robust and scientifically rigorous literature analysis, an experts team belonging to different sectors (public, business, academic, etc.) with a diverse cultural background was set up. In particular, it was made up of two experts in circular economy; one expert in multi-criteria decision methods; three digitalization experts; and one expert in business strategy. The experts team applying the well-known decision-making technique AHP defined the following elements of analysis:

Research questions identification (RQ). The main goal of the study was to investigate "How can digital technologies support a circular economy?". To answer to this point, the experts team identified the most representative research questions as follows:

- RQ1. How relevant is the EU policy on circular economy in the digital age?

- RQ2. What digital technologies might promote the benefits of circular economy?

- RQ3. In a digital age how business models could impact on CE?

- RQ4. What is the contribution coming from RESOLVE framework?

- RQ5. Which SDGs are more involved on CE?

Search criteria definition (SC). After the analysis of the several information sources (websites, reports, database, etc.) and after some coordination meetings, the seven experts to better address the SLR identified the five dimensions or criteria (C1. RESOLVE framework; C2. EU Eco-Innovation Plan; C3. Digital Technologies; C4. Business Models and C5. SDGs) that represent the bibliometric search criteria. In addition, to better characterize the literature survey 37 sub criteria have been identified as shown in Figure 5. The 37 sub criteria represent the investigation keywords to be used in the scientific database.

The weight of importance for each criterion was defined through the AHP as shown in Table 1. The experts' judgments were aggregated using the geometric mean as it better represents the variability of judgments expressed by different experts, as suggested by Prof. Saaty. Of course, the consistency index was also checked $(\mathrm{CI}<0.10)$.

It is important to remember that the bibliometric search criteria summarized in Table 1 represent the main research topics used to define the keywords to carry out the SLR. In particular, the experts team identified 37 specific keywords characterizing each criterion to perform the bibliometric analysis. Obviously, the experience and knowledge of the experts team are two focal points which were helpful to identify all keywords to select the most representative documents. Tables $2-6$ show the pairwise comparison matrices and weights for each criterion $(\mathrm{C} 1 ; \mathrm{C} 2 ; \mathrm{C} 3 ; \mathrm{C} 4 ; \mathrm{C} 5)$. 


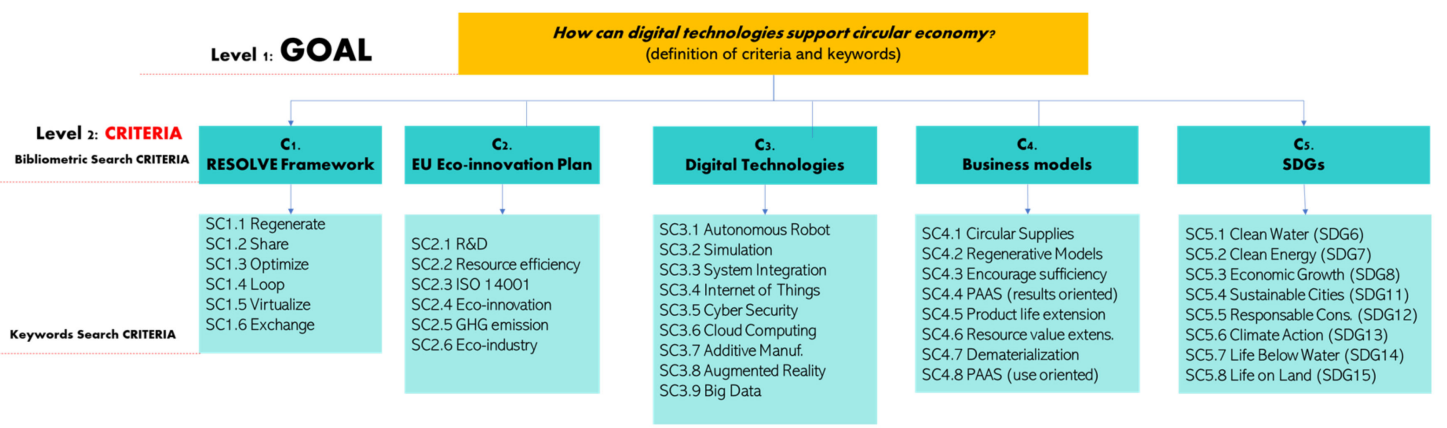

Figure 5. AHP model (Bibliometric Search CRITERIA and Keywords Search CRITERIA identification).

Table 1. AHP pairwise comparison matrix-Bibliometric search criteria and weights.

\begin{tabular}{lcccccc}
\hline Bibliometric Search CRITERIA & C1 & C2 & C3 & C4 & C5 & WEIGHT \\
\hline C1. RESOLVE Framework & 1 & 3 & 4 & 2 & 2 & 0.104 \\
C2. EU Eco-innovation Plan & & 1 & 3 & 2 & 3 & 0.393 \\
C3. Digital Technologies & & & 1 & 3 & 2 & 0.258 \\
C4. Business models & & & 1 & 2 & 0.093 \\
C5. SDGs & & & & & \\
\multicolumn{1}{c}{ Consistency Index } & & & & \\
\hline
\end{tabular}

Table 2. AHP pairwise comparison matrix—Bibliometric search keywords for C1 "RESOLVE Framework" and weights.

\begin{tabular}{lccccccc}
\hline Bibliometric Search SC1 (Keywords) & SC1.1 & SC1.2 & SC1.3 & SC1.4 & SC1.5 & SC1.6 & WEIGHT \\
\hline SC1.1 Regenerate & 1 & 3 & 3 & 2 & 3 & 3 & 0.327 \\
SC1.2 Share & & 1 & 2 & 3 & 2 & 2 & 0.216 \\
SC1.3 Optimize & & & 1 & $1 / 2$ & 2 & 2 & 0.120 \\
SC1.4 Loop & & & & 1 & 2 & 2 & 0.154 \\
SC1.5 Virtualize & & & & & 1 & $1 / 2$ & 0.084 \\
SC1.6 Exchange & \multicolumn{7}{c}{0.0689} \\
\hline \multicolumn{1}{c}{ Consistency Index } &
\end{tabular}

Table 3. AHP pairwise comparison matrix-Bibliometric search keywords for C2 "EU Eco-innovation Plan" and weights.

\begin{tabular}{lccccccc}
\hline Bibliometric Search SC2 & SC2.1 & SC2.2 & SC2.3 & SC2.4 & SC2.5 & SC2.6 & WEIGHT \\
\hline SC2.1 R\&D & 1 & 3 & 4 & 2 & $1 / 3$ & 2 & 0.224 \\
SC2.2 Resource efficiency & & 1 & 2 & 1 & $1 / 2$ & $1 / 3$ & 0.099 \\
SC2.3 ISO 14001 & & & 1 & $1 / 2$ & $1 / 3$ & $1 / 2$ & 0.065 \\
SC2.4 Eco-innovation & & & & 1 & $1 / 3$ & $1 / 2$ & 0.100 \\
SC2.5 GHG emission & & & & & 3 & 0.347 \\
SC2.6 Eco-industry & \multicolumn{7}{c}{0.0563} \\
\hline \multicolumn{1}{c}{ Consistency Index } &
\end{tabular}

Table 4. AHP pairwise comparison matrix-Bibliometric search keywords for C3 “Digital Technologies" and weights.

\begin{tabular}{|c|c|c|c|c|c|c|c|c|c|c|}
\hline Bibliometric Search SC3 & SC3.1 & SC3.2 & SC3.3 & SC3.4 & SC3.5 & SC3.6 & SC3.7 & SC3.8 & SC3.9 & WEIGHT \\
\hline SC3.1 Autonomous Robot & 1 & $1 / 3$ & $1 / 3$ & $1 / 2$ & 1 & $1 / 2$ & $1 / 3$ & $1 / 3$ & $1 / 4$ & 0.041 \\
\hline SC3.2 Simulation & & 1 & $1 / 2$ & 2 & 2 & 2 & 3 & 2 & $1 / 2$ & 0.150 \\
\hline SC3.3 System Integration & & & 1 & 2 & 3 & 3 & $1 / 2$ & 3 & $1 / 2$ & 0.160 \\
\hline SC3.4 Internet of Things & & & & 1 & 3 & 2 & $1 / 2$ & $1 / 2$ & $1 / 3$ & 0.080 \\
\hline SC3.5 Cyber Security & & & & & 1 & $1 / 3$ & $1 / 2$ & $1 / 2$ & $1 / 4$ & 0.045 \\
\hline SC3.6 Cloud Computing & & & & & & 1 & $1 / 2$ & $1 / 2$ & $1 / 3$ & 0.067 \\
\hline SC3.7 Additive Manuf. & & & & & & & 1 & 2 & $1 / 2$ & 0.136 \\
\hline SC3.8 Augmented Reality & & & & & & & & 1 & 2 & 0.090 \\
\hline SC3.9 Big Data & & & & & & & & & 1 & 0.227 \\
\hline Consistency Index & & & & & 0.0526 & & & & & \\
\hline
\end{tabular}


Table 5. AHP pairwise comparison matrix-Bibliometric search keywords for C4 "Business models" and weights.

\begin{tabular}{|c|c|c|c|c|c|c|c|c|c|}
\hline Bibliometric Search SC3 & SC4.1 & $\mathrm{SC} 4.2$ & SC4.3 & SC4.4 & SC4.5 & SC4.6 & SC4.7 & SC4.8 & WEIGHT \\
\hline SC4.1 Circular Supplies & 1 & 2 & 3 & 2 & 2 & 1 & $1 / 2$ & 2 & 0.179 \\
\hline SC4.2 Regenerative Models & & 1 & 2 & 1 & 2 & 2 & 1 & 1 & 0.152 \\
\hline SC4.3 Encourage sufficiency & & & 1 & $1 / 2$ & 2 & $1 / 2$ & $1 / 2$ & 2 & 0.089 \\
\hline SC4.4 PAAS (results oriented) & & & & 1 & 1 & 2 & 1 & 3 & 0.138 \\
\hline SC4.5 Product life extension & & & & & 1 & 3 & 1 & 2 & 0.120 \\
\hline SC4.6 Resource value extens. & & & & & & 1 & $1 / 2$ & 3 & 0.102 \\
\hline SC4.7 Dematerialization & & & & & & & 1 & 2 & 01.63 \\
\hline SC4.8 PAAS (use oriented) & & & & & & & & 1 & 0.053 \\
\hline Consistency Index & & & & \multicolumn{2}{|c|}{0.0704} & & & & \\
\hline
\end{tabular}

Table 6. AHP pairwise comparison matrix-Bibliometric search keywords for C5 "SDGs" and weights.

\begin{tabular}{|c|c|c|c|c|c|c|c|c|c|}
\hline Bibliometric Search SC3 & SC5.1 & SC5.2 & SC5.3 & SC5.4 & SC5.5 & SC5.6 & SC5.7 & SC5.8 & WEIGHT \\
\hline SC5.1 Clean Water (SDG6) & 1 & 2 & 3 & 1 & 1 & $1 / 2$ & $1 / 2$ & $1 / 2$ & 0.116 \\
\hline SC5.2 Clean Energy (SDG7) & & 1 & 2 & 1 & 2 & $1 / 2$ & $1 / 2$ & $1 / 2$ & 0.100 \\
\hline SC5.3 Economic Growth (SDG8) & & & 1 & 2 & 1 & $1 / 2$ & $1 / 2$ & $1 / 2$ & 0.081 \\
\hline SC5.4 Sustainable Cities (SDG11) & & & & 1 & 2 & $1 / 2$ & $1 / 2$ & $1 / 2$ & 0.092 \\
\hline SC5.5 Sustainable Cons. (SDG12) & & & & & 1 & $1 / 2$ & 2 & $1 / 2$ & 0.099 \\
\hline SC5.6 Climate Action (SDG13) & & & & & & 1 & 2 & 2 & 0.206 \\
\hline SC5.7 Life Below Water (SDG14) & & & & & & & 1 & 2 & 0.142 \\
\hline SC5.8 Life on Land (SDG15) & & & & & & & & 1 & 0.159 \\
\hline Consistency Index & & & & & & & & & \\
\hline
\end{tabular}

Analyzing the results in detail, it emerges that the most important criterion is C2. "European Eco-innovation Action Plan" (39.3\%) followed by C3. "Digital Technologies" (25.8\%). While, among the sub criteria the most important is SC2.5 "GHG emission" (34.7\%) followed by SC1.1 "Regenerate" (32.7\%). Figure 6 summarizes the most important results.

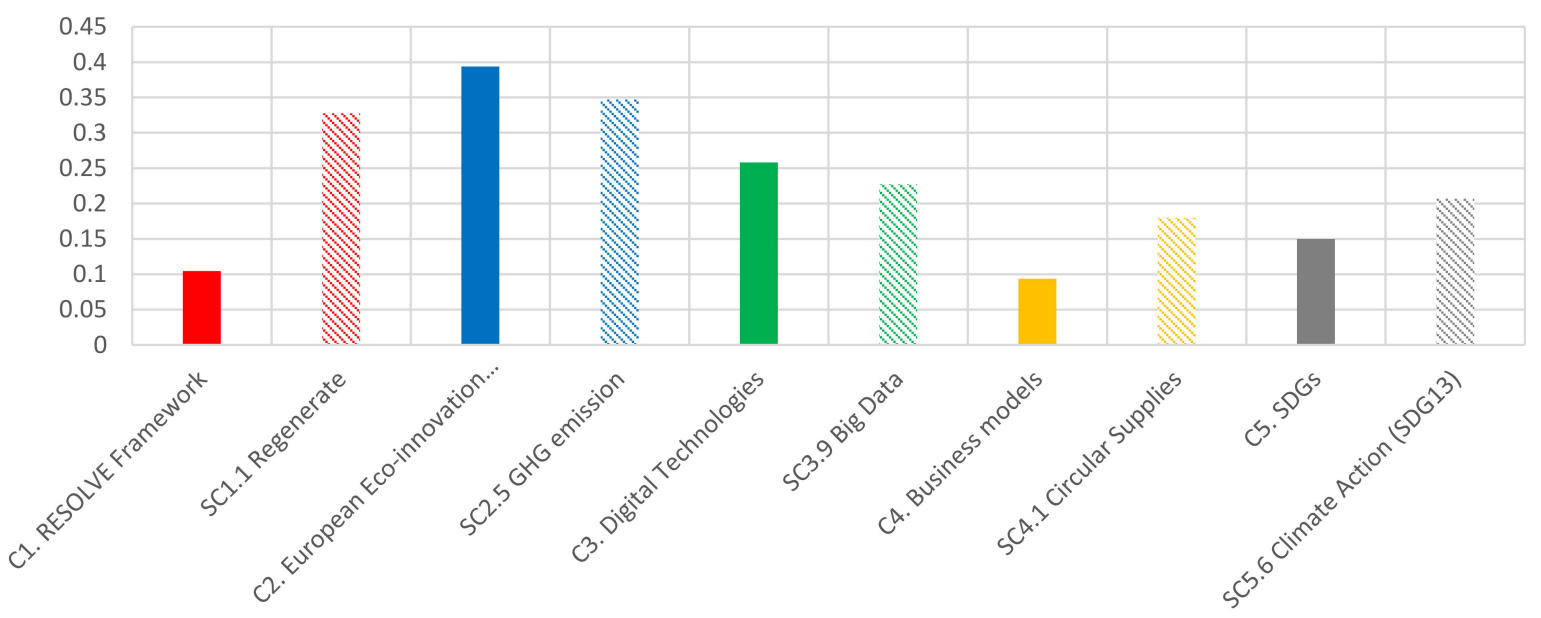

Figure 6. AHP model (weights for Search CRITERIA and Keywords Search CRITERIA).

Selection and Data collection process (SD). The experts team selected the documents using SCOPUS, one of the largest databases of scientific literature used worldwide in the scientific community and beyond. The documents were extracted by using the identified keywords (shown in Tables 2-6) of the topic under study using the logical operators AND and OR (supported by SCOPUS). In addition, only documents whit keywords included in the title were considered. Furthermore, for the definition of the final list of papers to be analyzed, the following exclusion, inclusion and quality criteria were considered as detailed below: 
1. Exclusion criteria definition (E). Documents were excluded according to the following exclusion criteria:

- E1: Documents not related to digital technologies.

- E2: Documents not related to CE.

- E3: Duplicate documents.

- E4: Documents in press.

2. Inclusion criteria definition (I). Documents were included according to the following inclusion criteria:

- I1: Documents published only in English.

- I2: Documents published only in peer-reviewed international journals (not included conference proceedings; editorials, chapter books, etc.).

3. Quality criteria definition (Q). Documents were analyzed according to the following quality criteria:

- Q1: Documents proposing different methodologies and approaches.

- Q2: Documents proposing different Enabling technology.

- Q3: Documents with impact factor, SJR or CiteScore.

Table 7 summarizes the number of items (without exclusions) identified according to the previous considerations.

Table 7. Query and $\mathrm{N}^{\circ}$ of items identified.

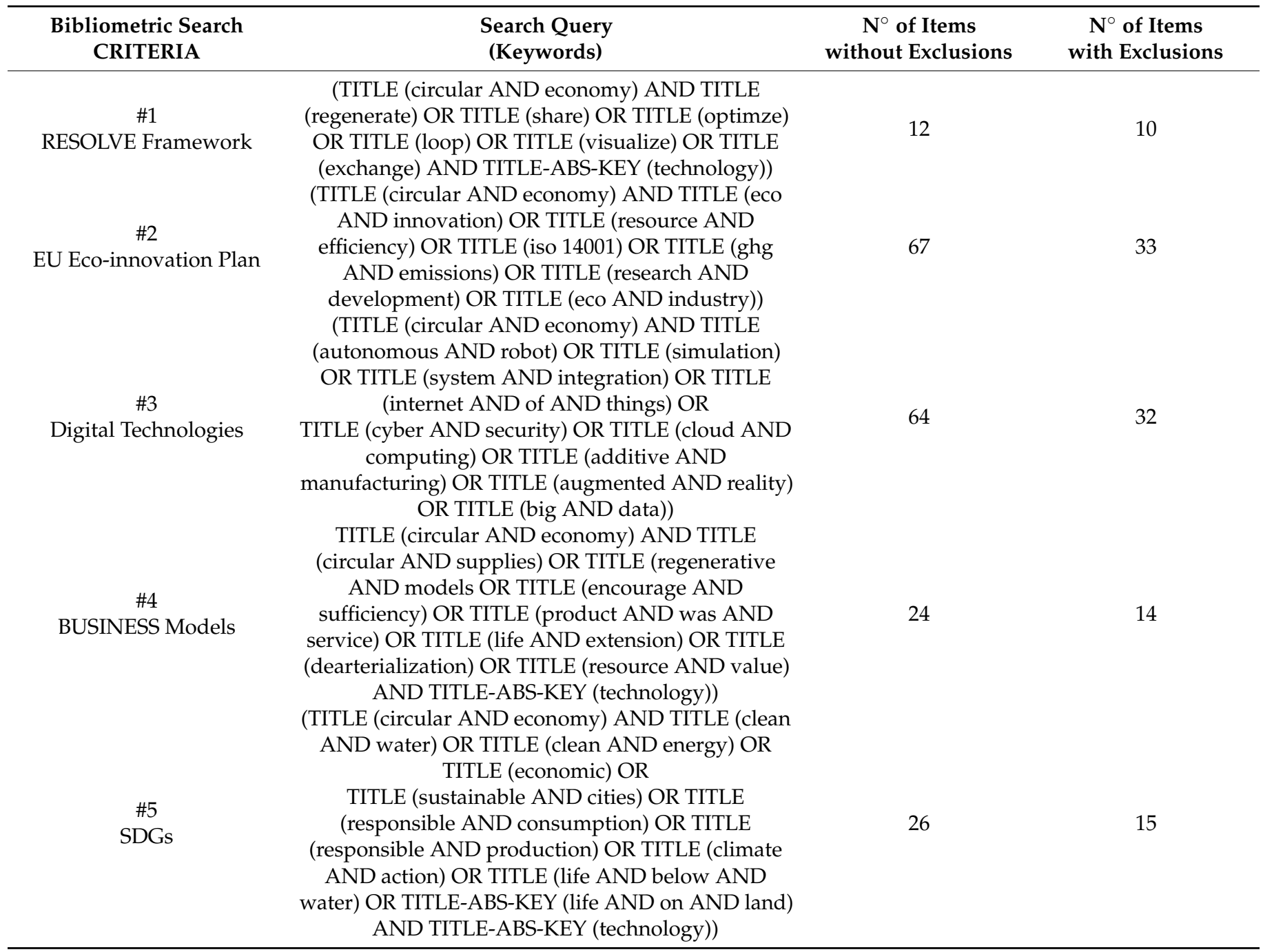


PRISMA 2020 flow diagram is shown in Figure 7. The PRISMA diagram is very useful since it provides an overview of the documents selected and analyzed according to the chosen parameters. As can be seen, the final number of documents analyzed was 104 .

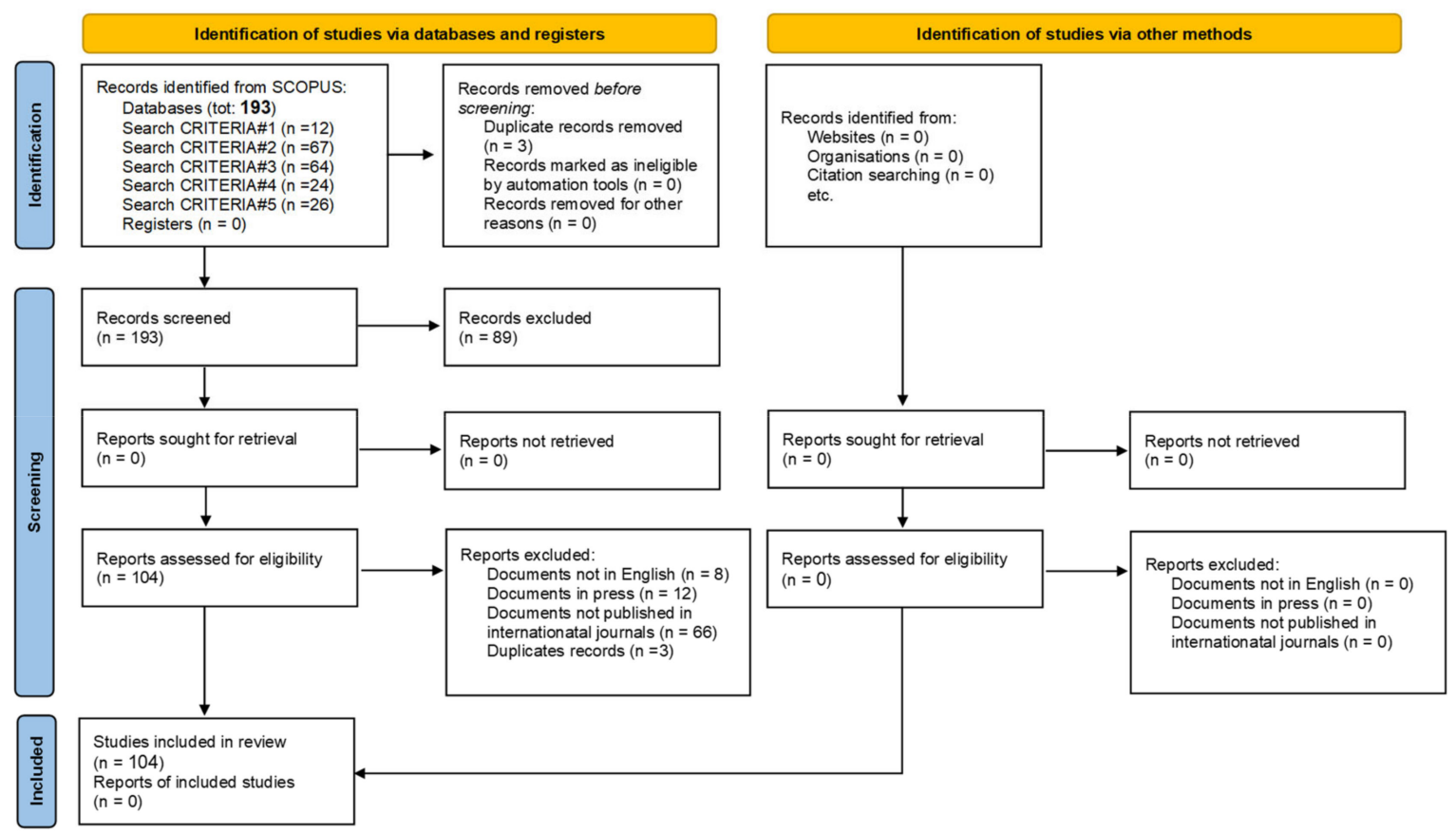

Figure 7. Selection of documents based on PRISMA.

\section{Results}

\subsection{Studies Selected and Characteristics}

In this section we provide a concise description of the main results obtained through A-PRISMA approach. The analysis of the results points out, as shown in the Figure 8, that the time span of the publications is quite recent. It is a result that is not surprising given the topicality of the topics analyzed.

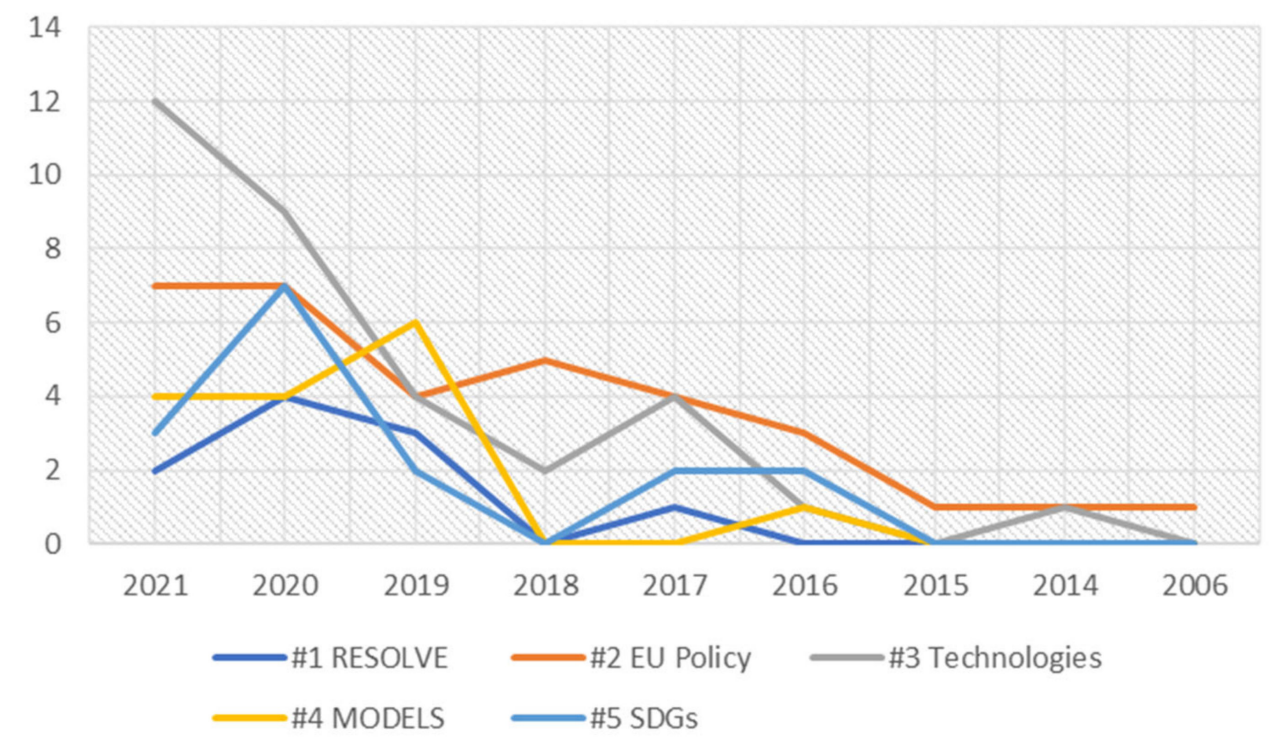

Figure 8. Number of documents by years (source: authors' elaboration from data SCOPUS).

It is interesting to note that the most cited documents (1650 citations) belong to the "SDGs" criterion. In fact, although the lowest number of selected publications belong 
to this criterion, the number of citations is the highest as shown in Figure 9. However, it should be noted that $89 \%$ of the citations are attributable to a single paper published by Ghisellini et al. [11]. The manuscript, published in 2016, provides a detailed literature review on CE (origins, principles, advantages and disadvantages). This would explain that it was taken as a reference on CE by the scientific community and therefore the large number of citations.

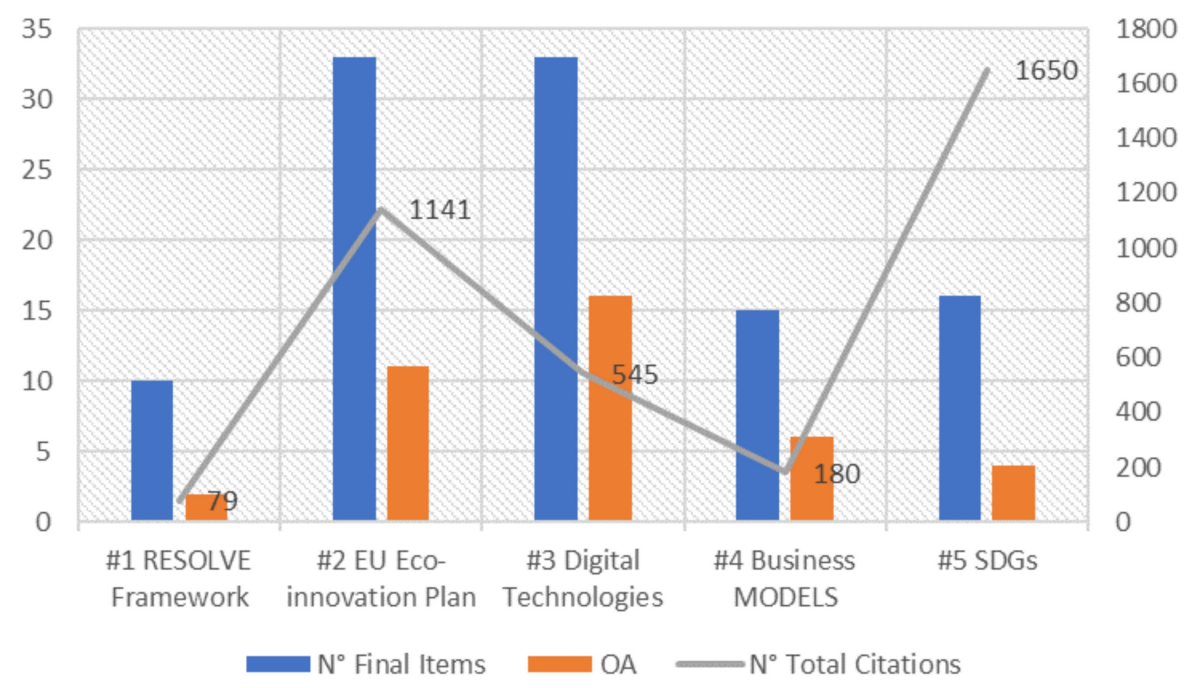

Figure 9. Classification of documents (source: authors' elaboration from data SCOPUS).

Figure 10 shows the relationship between the number of authors and the number of citations obtained. It is interesting to note that the greatest number of citations is independent of the number of authors.

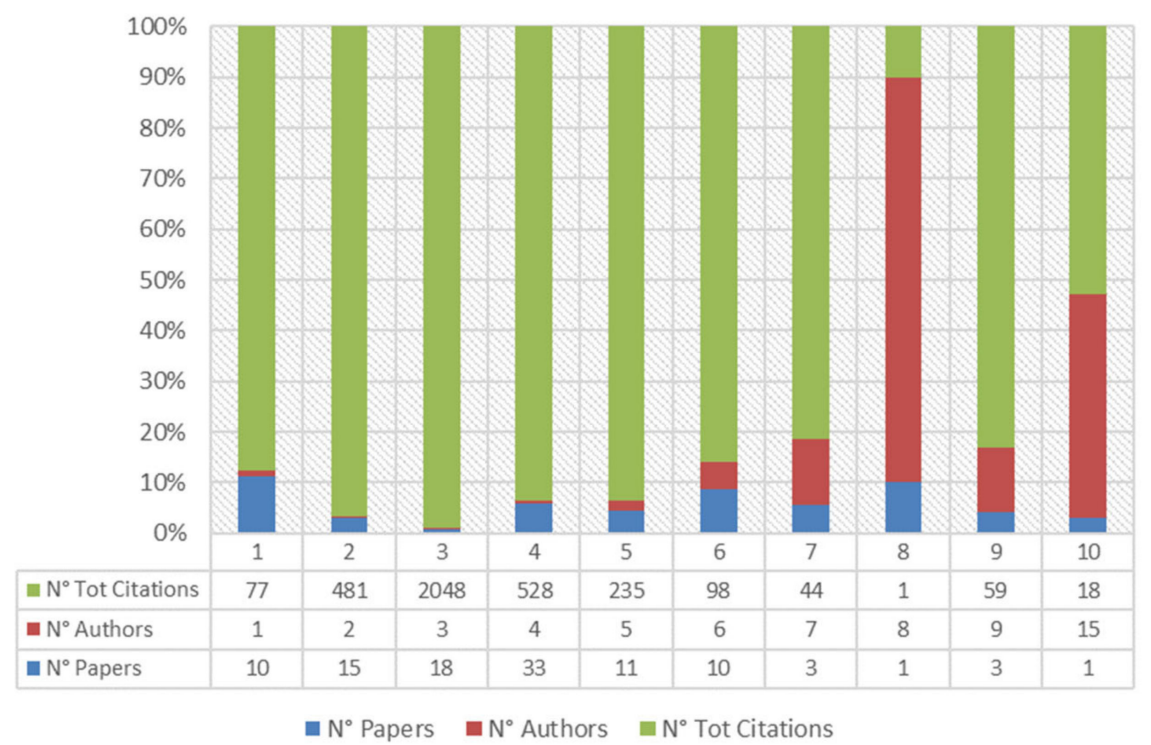

Figure 10. Relationship between the number of authors and the number of citations (source, authors' elaboration from data SCOPUS).

A detail of the most cited publications is shown in Table 8.

Considering the distribution of documents by country/territory according to the selected criteria, it emerges that Italy (C1. RESOLVE Framework; 20\%, United Kingdom (EU Eco-innovation Plan; 19\%; C3. Digital Technologies; 19\%), the United States (C4. Business MODELS; 21\%), and China (C5. SDGs; $15 \%$ ) are the most representative countries as shown in Figure 11. 
Table 8. The most cited documents (source: author's elaboration from data SCOPUS).

\begin{tabular}{|c|c|c|c|c|}
\hline Title & Year & Authors & $\mathbf{N}^{\circ}$ of Citations & Journal \\
\hline $\begin{array}{l}\text { Environmental and economic implications } \\
\text { of recovering resources from food waste } \\
\text { in a circular economy }\end{array}$ & 2019 & $\begin{array}{l}\text { Slorach, P.C., Jeswani, } \\
\text { H.K., Cuéllar-Franca, } \\
\text { R., Azapagic, A. }\end{array}$ & 48 & $\begin{array}{l}\text { Science of the Total } \\
\text { Environment }\end{array}$ \\
\hline $\begin{array}{c}\text { Eco-Efficiency Analysis of a Lithium-Ion } \\
\text { Battery Waste Hierarchy Inspired by } \\
\text { Circular Economy }\end{array}$ & 2017 & $\begin{array}{l}\text { Richa, K., Babbitt, } \\
\text { C.W., Gaustad, G. }\end{array}$ & 64 & $\begin{array}{c}\text { Journal of } \\
\text { Industrial Ecology }\end{array}$ \\
\hline $\begin{array}{l}\text { A review on circular economy: The } \\
\text { expected transition to a balanced interplay } \\
\text { of environmental and economic systems }\end{array}$ & 2016 & $\begin{array}{l}\text { Ghisellini, P., Cialani, } \\
\text { C., Ulgiati, S. }\end{array}$ & 1480 & $\begin{array}{l}\text { Journal of Cleaner } \\
\text { Production }\end{array}$ \\
\hline $\begin{array}{l}\text { Eco-innovation pathways to a circular } \\
\text { economy: Envisioning priorities through } \\
\text { a Delphi approach }\end{array}$ & 2019 & $\begin{array}{l}\text { de Jesus, A., Antunes, } \\
\text { P., Santos, R., } \\
\text { Mendonça, S. }\end{array}$ & 37 & $\begin{array}{l}\text { Journal of Cleaner } \\
\text { Production }\end{array}$ \\
\hline $\begin{array}{l}\text { When challenges impede the process: For } \\
\text { circular economy-driven sustainability } \\
\text { practices in food supply chain }\end{array}$ & 2019 & $\begin{array}{l}\text { Sharma, Y.K., Mangla, } \\
\text { S.K., Patil, P.P., Liu, S. }\end{array}$ & 37 & $\begin{array}{l}\text { Management } \\
\text { Decision }\end{array}$ \\
\hline
\end{tabular}

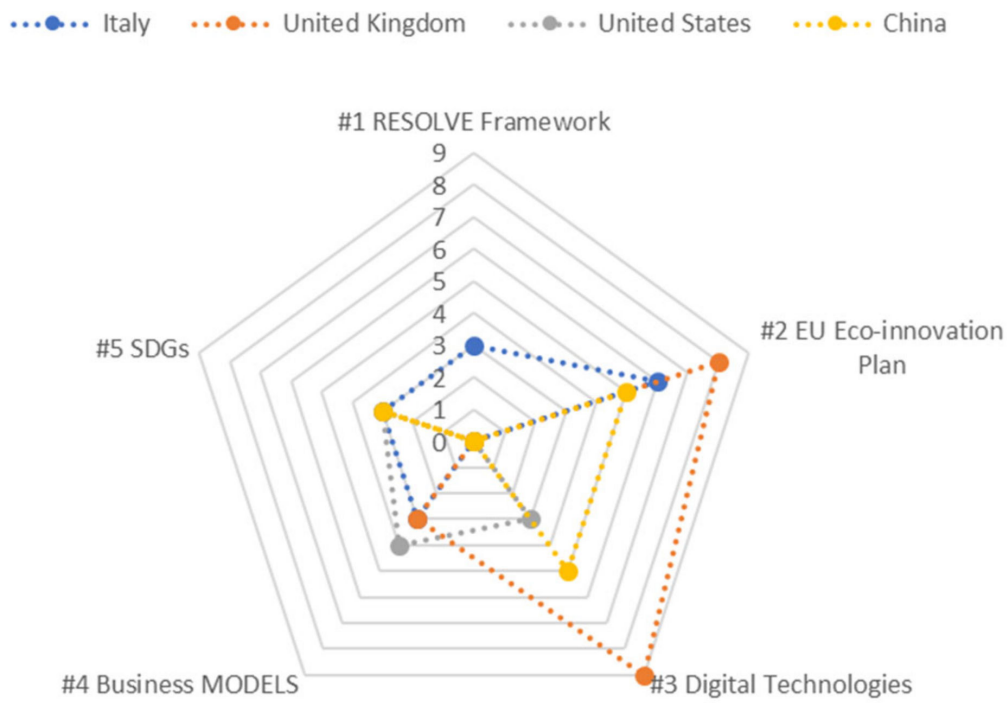

Figure 11. Documents by country/territory (source: authors' elaboration from data SCOPUS).

Table 9 shows the most prolific journals.

Table 9. The most prolific journals (source: author's elaboration from data SCOPUS).

\begin{tabular}{|c|c|c|c|c|c|}
\hline Title & Publisher & Cite Score $2020^{1}$ & SJR $2020^{2}$ & $\begin{array}{c}\text { Impact Factor } \\
2020\end{array}$ & Percentile \\
\hline $\begin{array}{l}\text { Journal of Cleaner } \\
\text { Production }\end{array}$ & Elsevier & 13.1 & 1.937 & 9.297 & 98th \\
\hline $\begin{array}{l}\text { Technological Forecasting } \\
\text { and Social Change }\end{array}$ & Elsevier & 12.1 & 2.226 & 8.593 & 97th \\
\hline $\begin{array}{c}\text { Business Strategy and The } \\
\text { Environment }\end{array}$ & Wiley-Blackwell & 10.3 & 2.123 & 10.302 & 98th \\
\hline Ecological Economics & Elsevier & 9.1 & 1.917 & 5.389 & 95th \\
\hline $\begin{array}{l}\text { Resources, Conservation } \\
\text { and Recycling }\end{array}$ & Elsevier & 14.7 & 2.468 & 10.204 & 99th \\
\hline $\begin{array}{l}\text { Science of the Total } \\
\text { Environment }\end{array}$ & Elsevier & 10.5 & 1.795 & 7.963 & 96th \\
\hline Sustainability (Switzerland) & MDPI & 3.9 & 0.612 & 3.251 & 84th \\
\hline
\end{tabular}

${ }^{1}$ CiteScore measures average citations received per document published in the serial. ${ }^{2}$ SCImago Journal Rank measures weighted citations received by the serial. Citation weighting depends on subject field and prestige (SJR) of the citing serial. 
Meanwhile, Figure 12 shows time distribution of publications and citations. In particular, it emerges that the most popular journal is the Journal of Cleaner Production (16\%), followed by Technological Forecasting and Social Change (7\%), and Sustainability (Switzerland) (6\%).

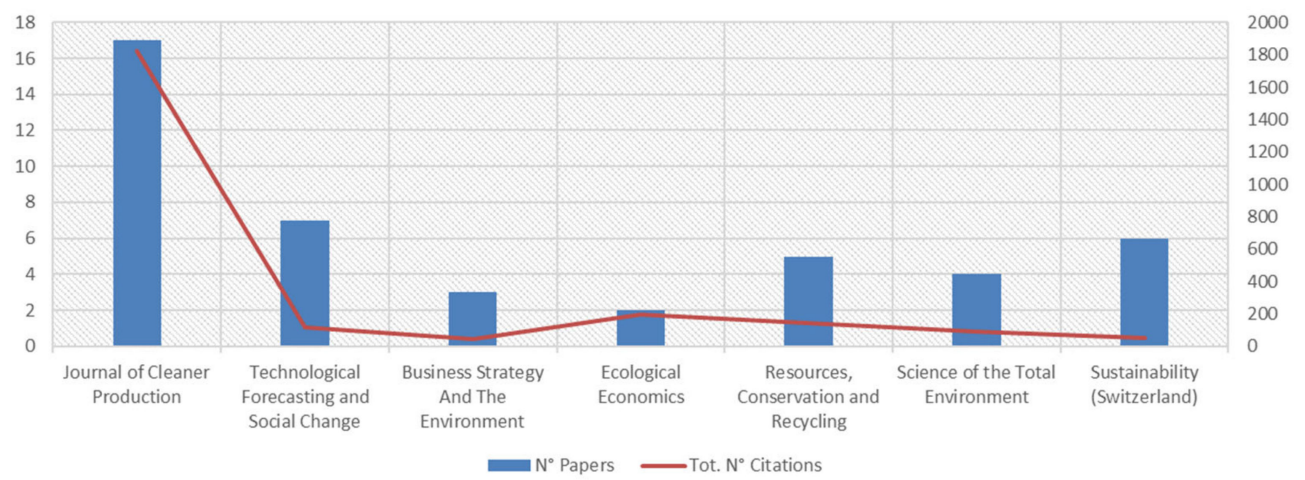

Figure 12. Time distribution of publications and citations (source: authors' elaboration from data SCOPUS).

It is interesting to note that it seems the number of citations is related to the journal's scientific reputation in the scientific community.

The most used keywords are shown in Figure 13.

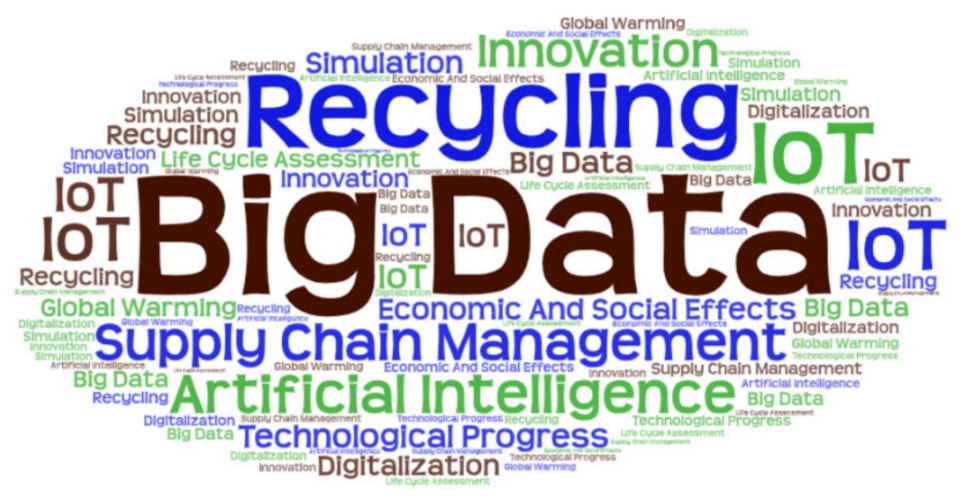

Figure 13. Most used keywords (source: authors' elaboration from data SCOPUS).

Figure 14 shows the research areas most covered by the published documents.

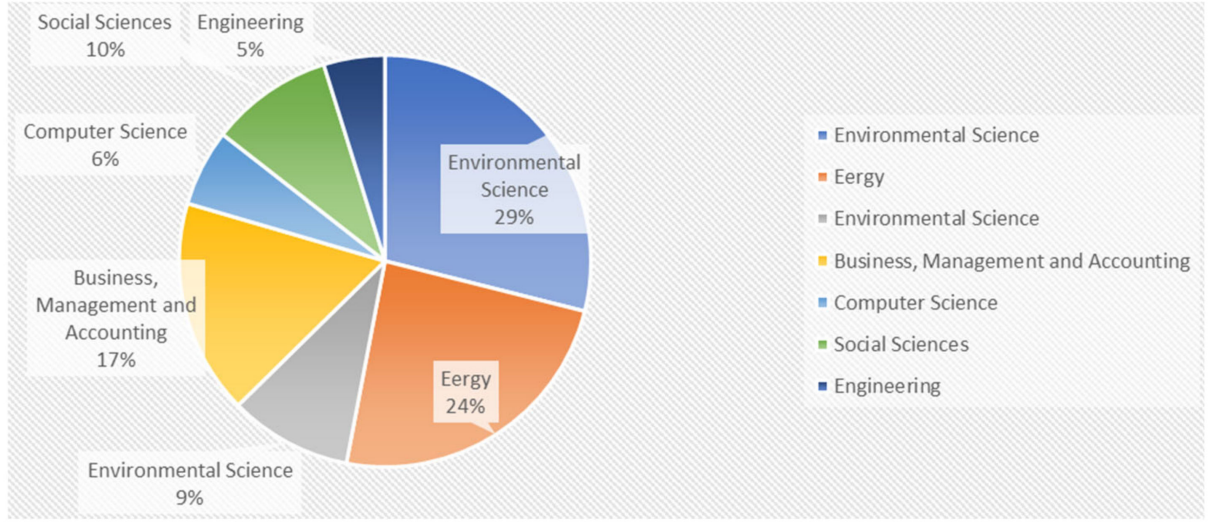

Figure 14. Subject area (source: authors' elaboration from data SCOPUS).

Analyzing the documents by founding sponsor, heterogeneity emerges. However, the results show an interesting trend from a European policy point of view. In fact, it emerges that the main funds are those of the EU: European Commission (40\%); Horizon 
2020 Programme (36\%); European Regional Development Fund (12\%); European Institute of Innovation and Technology (8\%); and LIFE programme (4\%).

\subsection{Results of Individual Studies}

This section provides an overview of the main documents analyzed. For clarity and punctuality, the analysis is organized according to the Bibliometric Search CRITERIA (defined in Section 3.2).

\section{\#1 RESOLVE Framework (10 documents)}

The documents belonging to this selection addressing issues related to the RESOLVE framework (regenerate, share, optimize, loop, virtualize, and exchange). Table 10 summarizes a classification of documents by year, type of publication and main focus. Analyzing in detail, it emerges that, recently, Contreras-Lisperguer et al. [12] evaluated, through a simulation model, a new solar photovoltaic (PV) material recovery system. Tapia et al. [13] analyzed the role of territorial factors in closed-loop systems. In addition, Velvizhi et al. [14] investigated how biodegradable and non-biodegradable fraction of municipal solid waste could be treated by advanced biological processes. According to the authors, the use of the IoT could represent an opportunity for intelligent waste management. A different point of view is analyzed by Atabaki et al. [15] who developed an optimization models based on linear and possibilistic programming for closed-loop supply chain of durable products. A case study on the development of models on the closure of both technical and biological circuits proposed in Finland is proposed by Vanhamaki et al. [16]. The use of the recycled anion exchange membranes avoiding their disposal in landfills was proposed by Lejarazu-Larranaga et al. [17]. Similarly, Sharma et al. [18] demonstrated the recycling of spent electrocatalyst from a PEMFC electrode is demonstrated. Roy et al. [19] developed a closed loop system for conservation of fresh water at household user point. While, Conforto [20] proposed an innovative platform, based on machine learning and blockchain etc., for a for proper waste management. Finally, Sposato et al. [21] explored the role of sharing economy in products and services from a life cycle thinking perspective.

Table 10. Classification of documents belonging to \#1 RESOLVE Framework cluster.

\begin{tabular}{cllcc}
\hline Authors & Ref. & Year & Type of Publication & Main Focus \\
\hline Contreras-Lisperguer R., et al. & {$[12]$} & 2021 & Theoretical/Application & Recycling \\
Tapia C., et al. & {$[13]$} & 2021 & Review & Place-based policies \\
Velvizhi G., et al. & {$[14]$} & 2020 & Theoretical & Municipal solid waste \\
Atabaki M.S., et al. & {$[15]$} & 2020 & Theoretical & Closed-loop supply chain \\
Vanhamäki S., et al. & {$[16]$} & 2020 & Case Study & Biological loops \\
Lejarazu-Larrañaga A., et al. & {$[17]$} & 2020 & Case Study & Recycling \\
Sharma R., et al. & {$[18]$} & 2019 & Case Study & Recycling \\
Roy M., et al. & {$[19]$} & 2019 & Case Study & Recycling \\
Conforto R. & {$[20]$} & 2019 & Theoretical/Application & Recycling/Recovery \\
Sposato P., et al. & {$[21]$} & 2017 & heoretical & Sharing economy \\
\hline
\end{tabular}

\section{\#2 EU Eco-innovation Plan (33 documents)}

The manuscripts belonging to this cluster are quite heterogeneous. In addition, qualitative approaches rather than case studies or applications are proposed. Table 11 summarizes a classification of documents by year, type of publication and main focus. 
Table 11. Classification of documents belonging to \#2 EU Eco-innovation Plan cluster.

\begin{tabular}{|c|c|c|c|c|}
\hline Authors & Ref. & Year & Type of Publication & Main Focus \\
\hline Meseguer-Sánchez V., et al. & {$[22]$} & 2021 & Review & Degree advancement of the CE \\
\hline Vence X. and Pereira Á. & [23] & 2019 & Theoretical & Eco-innovation \\
\hline Wang N., et al. & {$[24]$} & 2018 & Theoretical & Urban sustainability \\
\hline Lee R.P., et al. & {$[25]$} & 2017 & Theoretical & Resource efficiency \\
\hline Strothman P., et al. & {$[26]$} & 2017 & Theoretical & Resource efficiency \\
\hline Lee R.P., et al. & {$[27]$} & 2017 & Theoretical & Resource efficiency \\
\hline Belmonte-Ureña L.J., et al. & {$[28]$} & 2021 & Review & SDGs and CE \\
\hline Maldonado-Guzmán G., et al. & [29] & 2021 & Review & Eco-innovation \\
\hline Cainelli G., et al. & {$[30]$} & 2020 & Theoretical & Eco-innovation \\
\hline Novelli V., et al. & [31] & 2018 & Theoretical & Eco-innovation \\
\hline Pagotto M. and Halog A. & {$[32]$} & 2016 & Theoretical/Application & Resource efficiency \\
\hline Sauvé S., et al. & [33] & 2016 & Theoretical & Environmental protection \\
\hline Lu Y. & [34] & 2014 & Case study & Marine circular economy \\
\hline Johl S.K. and Toha M.A. & [35] & 2021 & Theoretical/Application & Eco-innovation \\
\hline Kiefer C.P., et al. & [36] & 2021 & Theoretical/Application & Eco-innovation \\
\hline Magazzino C., et al. & [37] & 2021 & Theoretical & Municipal solid waste \\
\hline Demirel P. and Danisman G.O. & [38] & 2019 & Theoretical & Eco-innovation \\
\hline Laso J., et al. & [39] & 2018 & Application & Eco-efficiency \\
\hline Ncube A., et al. & {$[40]$} & 2021 & Application & Resource efficiency \\
\hline Heath G.A., et al. & [41] & 2020 & Application & Recycling \\
\hline Bartie N.J. et al. & [42] & 2020 & Application & Resource efficiency \\
\hline Garcia-Muiña F.E., et al. & [43] & 2019 & Theoretical/Application & Eco-design \\
\hline Durán-Romero G., et al. & {$[44]$} & 2020 & Theoretical & Climate Change \\
\hline Ramkumar S. & [45] & 2020 & Case Study & Eco-innovation \\
\hline $\begin{array}{l}\text { Matrapazi V.K. and } \\
\text { Zabaniotou A. }\end{array}$ & {$[46]$} & 2020 & Application & Eco-social innovation \\
\hline Charles R.G., et al. & {$[47]$} & 2018 & Theoretical/Application & Recovery \\
\hline $\begin{array}{l}\text { Stankevičienè J. and } \\
\text { Nikanorova } \mathrm{M} \text {. }\end{array}$ & {$[48]$} & 2020 & Theoretical & Eco-innovation \\
\hline de Jesus A., et al. & [49] & 2019 & Theoretical & Eco-innovation \\
\hline de Jesus A., et al. & [50] & 2016 & Review & Eco-innovation \\
\hline de Jesus A. and Mendonça S. & [51] & 2018 & Review/Survey & Eco-innovation \\
\hline Di Maio F., et al. & [52] & 2017 & Theoretical/Application & Resource efficiency \\
\hline Ma S., et al. & [53] & 2015 & Theoretical/Application & Resource efficiency \\
\hline Taiyang Z., et al. & {$[54]$} & 2006 & Case Study & Efficiency of resource \\
\hline
\end{tabular}

Several authors have proposed literature review analysis or scenario analysis in order to analyze the factors enabling the principles of the circular economy [22-27] or the relationship between sustainable development goals (SDGs) and CE [28] or the relationship between innovation and CE the automotive sector [29]. In this context, Cainelli et al. [30] analyzed the role of the environment to promote the adoption of resource efficiency-oriented eco-innovations. Meanwhile, some other authors analyzed the relationship between ecoinnovation and firm financial performance in their countries to achieve a sustainable transition [31-34]. For example, Johl S.K. and Toha [35] performed a study in 31 Malaysian public energy companies; Kiefer et al. [36] carried out a similar study in Spain. The waste generation management problem is investigated by Magazzino et al. [37] who proposed an experiment based on artificial neural networks to understand how to interact within a complex ecosystem such as between the environment and waste. Demirel and Danisman [38] investigated the impact of the practice of CE across 28 European countries in 2016. In order to analyze the environmental impacts of products and processes, some authors have developed life cycle assessment (LCA) studies [39]. For example, Ncube et al. [40] developed an LCA study in the brick manufacturing sector in Zimbabwe. Heath G.A., et al. [41] proposed an LCA study for photovoltaic (PV) modules. Bartie et al. [42] demonstrated the enabling role of metallurgical infrastructure using LCA. An example of the introduction of the circular economy paradigm in an Italian ceramic industry is provided by Garcia-Muiña et al. [43] that developed an LCA/LCC model to 
evaluate an alternative composition of the current ceramic body. Durán-Romero et al. [44] analyzed from a theoretical point of view the relationship between climate change and CE. A different point of view is analyzed by Ramkumar [45] that, through the analysis of a case study related to the Jaguar Land Rover, demonstrates the importance of relationships with suppliers to promote product innovation from a CE perspective. Similarly, Matrapazi and Zabaniotou [46] demonstrated the technical and economic feasibility of reusing coffee grounds through a pyrolysis process. Results have been presented within an EU LIFE + project between Aristotle University (Greece) and co-developed with an Irish company. Charles et al. [47] developed a business model for the recovery of platinum from waste thermocouples which is then used for the preparation of catalytic electrodes suitable for dye-sensitized solar cell production. An interesting and original research is proposed by Stankevičienė and Nikanorova [48]. MCDM methods (using MULTIMOORA and TOPSIS methods) are used to assess to assess the eco-innovation worldwide in the context of CE. Similarly, de Jesus et al. [49] used Delphi method to explores how to implement principles of CE and the fundamental strategies. de Jesus is one of the most prolific authors in this cluster. Previously, in 2016 he carried out an extensive literature review on CE and eco-innovation [50]. In 2018, he discussed the different factors that favor or hinder the development of a CE [51]. Some authors have developed methods for "measuring" circularity. This is a very important aspect. In this context, Di Maio et al. [52] proposed a new value-based indicator to assess the performance of actors in the supply chain in terms of resource efficiency and circular economy. Ma et al., [53] developed a set of tools within a phosphorus chemical firm to improve its economic benefit, resource efficiency, waste recycling rate, and eco-efficiency. Finally, Taiyang Z., et al. [54] proposed an analytical framework for a comprehensive assessment of regional circular economic growth of Jiangsu Province.

\section{\#3 Digital Technologies (32 documents)}

In this cluster belong the manuscripts that expressly propose the use of technologies to promote the principles of the CE [55-58]. Table 12 summarizes a classification of documents by year, type of publication and main focus. Several authors investigate, through multi-criteria decision-making methods (i.e., PROMETHEE II method, VIKOR, best-worst Method, SWARA, Fuzzy ANN etc.) the barriers that hinder the use of technologies such as the use of IoT [59-61], or big data [62-66]. Among other technologies, some authors propose the use of simulations to produce an economic analysis of the processes or as tool to train [67-71]. Some other investigate the use of additive manufacturing for various applications such as the use of materials with a lower environmental impact [72-74]. Some authors propose the use of digital technologies to optimize waste management. In this regard, Wang et al. [75] proposed the use of IoT in China to manage household waste. Mangrini et al., [76] argued that the integration of IoT and blockchains can help the producers manage the end-of-life of electrical and electronic equipment (EEE). Their study is contextualized in Italy. Many authors argue that the implementation of CE principles supported by digital technologies represents an opportunity to be pursued [77-80]. However, as argued by Hatzivasilis et al. [81], the lack of interoperable solutions slows down the process of innovation and ecological transition. New communication protocols and the introduction of 5th generation mobile networks (5G) would be needed for new business models [82-85].

Table 12. Classification of documents belonging to \#3 Digital Technologies cluster.

\begin{tabular}{ccccc}
\hline Authors & Ref. & Year & Type of Publication & Main Focus \\
\hline Modgil S., et al. & {$[55]$} & 2021 & Case Study & Big Data \\
Nobre G.C., Tavares E. & {$[56]$} & 2020 & Review & IoT/Big Data \\
Nobre G.C., Tavares E. & {$[57]$} & 2020 & Review & IoT/Big Data \\
Górecki J. & {$[58]$} & 2020 & Review & Barriers CE \\
Cui Y., et al. & {$[59]$} & 2021 & Theoretical/Application & Barriers IoT/SWARA \\
Jinil Persis D., et al. & {$[60]$} & 2021 & Theoretical & Barriers IoT \\
Miaoudakis A., et al.. & {$[61]$} & 2020 & Theoretical & Barriers IoT \\
Kazançoğlu Y., et al. & {$[62]$} & 2021 & Theoretical/Application & Barriers Big Data/VIKOR \\
Awan U., et al. & {$[63]$} & 2021 & Review/Survey & Big data analytics capabilities \\
Kamble S.S., et al. & {$[64]$} & 2021 & Review & Big Data-driven/ PROMETHEE \\
\hline
\end{tabular}


Table 12. Cont.

\begin{tabular}{ccccc}
\hline Authors & Ref. & Year & Type of Publication & Main Focus \\
\hline Bag S., et al. & {$[65]$} & 2021 & Review & Big data analytics capabilities \\
Big Data/Supply Chain \\
Del Giudice M., et al. & {$[66]$} & 2020 & Review/Survey & Simulation \\
Waudby H. and Zein S.H. & {$[67]$} & 2021 & Theoretical/Application & Simulation \\
de la Torre R., et al. & {$[68]$} & 2021 & Review & Simulation \\
Li X. and Luo F. & {$[69]$} & 2021 & Theoretical/Application & Simulation \\
Utrilla P.N.-C., et al. & {$[70]$} & 2020 & Theoretical/Application & Simulation \\
Abadías Llamas A., et al. & {$[71]$} & 2020 & Theoretical/Application & Additive Manufacturing \\
Sauerwein M., et al. & {$[72]$} & 2020 & Theoretical/Application & Additive Manufacturing \\
Sauerwein M., et al. & {$[73]$} & 2019 & Review & Additive Manufacturing \\
Giurco D., et al. & {$[74]$} & 2014 & Theoretical/Application & IoT/Smart waste management \\
Wang B., et al. & {$[75]$} & 2021 & Theoretical & IoT/Blockchain/WEEE \\
Magrini C., et al. & {$[76]$} & 2021 & Theoretical & Big Data \\
Gupta S., Chen H., et al. & {$[77]$} & 2019 & Review & Simulation \\
Wang X. & {$[78]$} & 2019 & Theoretical/Application & Simulation \\
Charnley F., et al. & {$[79]$} & 2019 & Theoretical & Urban planning \\
van der Leer J., et al. & {$[80]$} & 2018 & Review & IoT/5G/Cloud \\
Hatzivasilis G., et al. & {$[81]$} & 2018 & Theoretical & Simulation \\
Lieder M., et al. & {$[82]$} & 2017 & Theoretical & Simulation \\
Lieder M., et al. & {$[83]$} & 2017 & Theoretical & IoT \\
Andreopoulou Z. & {$[84]$} & 2017 & Theoretical & IoT \\
Reuter M.A. & {$[85]$} & & &
\end{tabular}

\section{\#4 BUSINESS Models (14 documents)}

The manuscripts belonging to this cluster address the $\mathrm{CE}$ issue from different points of view with the common goal of identifying business models to implement the CE. Table 13 summarizes a classification of documents by year, type of publication and main focus.

Table 13. Classification of documents belonging to \#4 Business Models cluster.

\begin{tabular}{ccccc}
\hline Authors & Ref. & Year & Type of Publication & Main Focus \\
\hline Kumar S., et al. & {$[86]$} & 2021 & Theoretical & Agriculture supply chain \\
Nandi S., et al. & {$[87]$} & 2021 & Theoretical & Supply chain management \\
Nandi S., et al. & {$[88]$} & 2020 & Theoretical & Supply chain management \\
Kazancoglu I., et al. & {$[89]$} & 2021 & Theoretical & Supply chain management \\
Ciccullo F., et al. & {$[90]$} & 2021 & Theoretical & Supply chain management \\
Safiullin M.R., et al. & {$[91]$} & 2020 & Theoretical & Supply chain management \\
Alizadeh-Basban N., and Taleizadeh & {$[92]$} & 2020 & Theoretical/Application & Remanufacturing \\
Tacchini M., et al. & {$[93]$} & 2019 & Case Study & Waste-revaluation \\
Clark N., et a. & {$[94]$} & 2019 & Survey & Packaging \\
Sharma Y.K., et al. & {$[95]$} & 2019 & Case Study & Food sector \\
Kasulaitis B.V., et al. & {$[96]$} & 2019 & Theoretical & Dematerialization \\
Douguet J.-M., et al. & {$[97]$} & 2019 & Theoretical & Aggregate sector \\
Daú G., et al. & {$[98]$} & 2019 & Theoretical & Supply chain management \\
O'Connor M.P., et al. & {$[99]$} & 2016 & Theoretical & Supply chain management \\
\hline
\end{tabular}

However, as Kumar et al., [86] recently highlighted, there are still many obstacles in many sectors (including agriculture) to implement new business models of ecological transition. In addition, as argued by Nandi et al. [87,88] today digitalization could represent the only post-COVID19 opportunity for many companies. Of the same opinion is Kazancoglu et al. [89] who discusses potential implications on enhancing corporate environmental performance of a business. In fact, some authors point out the benefits that technologies could have on the entire supply chain. In this regard it is interesting to mention the research conducted by Ciccullo et al. [90], that highlights that the adoption of different technological options could also prevent food waste in the agri-food supply chain. Or, as argued by Safiullin et al. [91] it could be increasing the stability of the 
economy through supply chain management. An interesting approach is proposed by Alizadeh-Basban and Taleizadeh [92] that argued the need to balance all material flows of all stakeholder belonging to the supply chain. To this end they develop a simulation game to analyze all relationships and flows of materials. A real case study is proposed by Tacchini et al. [93] that analyze how to re-evaluate the wine supply chain avoiding chemical, antioxidant and antimicrobial characterizations. There are several studies that, through surveys, aim to identify the potential of CE principles in different economic sectors. For example, Clark et al. [94] through a survey across the UK food packaging supply chain they identify the potential to reduce waste in packaging. Sharma et al. [95] conducted a case study of a dairy food processing company in India to identify the challenges to CE in the food value chain. A different approach is proposed by Kasulaitis et al. [96] that investigated the potential efficacy of "natural" dematerialization and CE. It emerges that companies with greater technological capabilities intend to accelerate the internal processes of digitalization, dematerialization of documentation, and automation of business processes aim at a highly digitized 4.0 organizational model. Douguet et al. [97] investigated the sustainability scenarios in the aggregates sector in France, highlighting the opportunities from a circular economy perspective. A very potential topic is analyzed by Daú et al. [98] that examined the healthcare sustainable supply chain. Finally, a strategy for material supply chain sustainability in the electronics industry is proposed by O'Connor [99].

\section{\#5 SDGs (15 documents)}

Documents directly linked to the principles of some SDGs belong to this cluster (i.e., Clean Water (SDG6); Clean Energy (SDG7); Economic Growth (SDG8); Sustainable Cities (SDG11); Sustainable Consumption and Production (SDG12); Climate Action (SDG13); Life Below Water (SDG14) and Life on Land (SDG15)). Table 14 summarizes a classification of documents by year, type of publication, and main focus. Recently, Rashid and Shahzad [100] analyzed the potential benefits of organic food waste recycling both from a technical and an economic point of view. The study is contextualized in Saudi Arabia's Mecca. Similarly, Slorach et al. [101] investigated the recovery energy and material resources from food waste in the UK. Chen [102] in his research explained the positive effect of circular economy models to ensure more sustainable cities. Llera-Sastres et al. [103] proposed a method to analyze the socio and economic impacts of power-to-gas to support effective policymaking and energy companies' decision-making processes. Many studies highlight the importance for decision makers to define specific national and regional policies in order to promptly promote the principles of the circular economy $[11,104]$. Specific actions are essential to foster sustainable production, consumption, and the use of essential raw materials, a fact made clear by Tian et al. [105] and by Micari et al. [106], respectively. In their studies, a technical environmental assessment of wastewater treatment facilities and water softening treatment is provided. Kleines et al. [107] explored the reuse and recycling of plastics. Mathur et al. [108] explored the opportunities offered by an effective technology process to manage photovoltaic waste. A very current perspective is addressed by Lee [109] that investigated the use of biohydrogen in Asian countries. Chen et al. [110] evaluated the feasibility and potential benefits of this circular rice production system into Mediterranean production. A new and promising topic is analyzed by Stadler et al. [111] that addressed the economic viability of aquaponic systems under Dutch conditions and described possible socio-economic scenarios. The problem of water treatment in the Netherlands is analyzed also by Roest et al. [112]. Finally, a very current issue for the automotive industry is developed by Richa et al. [113] that analyzed the end-of-life of lithium-ion batteries from electric vehicles (EVs).

Table 14. Classification of documents belonging to \#5 SGDs cluster.

\begin{tabular}{ccccc}
\hline Authors & Ref. & Year & Type of Publication & Main Focus \\
\hline Rashid M.I. and Shahzad K. & {$[100]$} & 2021 & Theoretical/Application & Waste management \\
Slorach P.C., et al. & {$[101]$} & 2019 & Theoretical/Application & Waste management \\
Chen C.-W. & {$[102]$} & 2021 & Theoretical & Sustainable cities \\
Llera-Sastres E., et al. & {$[103]$} & 2020 & Theoretical & Energy transition \\
Zhou X., et al. & {$[104]$} & 2020 & Theoretical & Technological progress \\
\hline
\end{tabular}


Table 14. Cont.

\begin{tabular}{ccccc}
\hline Authors & Ref. & Year & Type of Publication & Main Focus \\
\hline Tian X., et al. & {$[105]$} & 2020 & Theoretical/Application & Water resource recovery \\
Micari M., et al. & {$[106]$} & 2020 & Theoretical/Application & Water resource recovery \\
Kleines L. & {$[107]$} & 2020 & Theoretical & Waste management \\
Mathur N., et al. & {$[108]$} & 2020 & Theoretical/Application & Material recovery \\
Lee D.-H. & {$[109]$} & 2020 & Theoretical & Energy transition \\
Chen W., et al. & {$[110]$} & 2019 & Theoretical & Material recovery \\
Stadler M.M., et al. & {$[111]$} & 2017 & Theoretical/Application & Water resource recovery \\
Roest K., et al. & {$[112]$} & 2016 & Theoretical/Application & Water resource recovery \\
Richa K., et al. & {$[113]$} & 2017 & Theoretical/Application & Material recovery \\
Ghisellini P., et al. & {$[11]$} & 2016 & Theoretical & Resource efficiency \\
\hline
\end{tabular}

\section{Discussion and Lessons learned}

\subsection{Main Contributions of the Research}

The research allows us to fill some gaps in the literature. In particular, it has been possible to investigate how digital technologies support a circular economy. Generally, the published research on this topic has two main weaknesses. The first is that they analyzed only one digital technology or a few of them. The second one is that they do not approach the problem from a holistic and global point of view but they are focused on certain aspects or on specific sectors. Instead, unlike other research, our study analyzes the problem in terms of five dimensions: the RESOLVE Framework; EU Eco-innovation Plan; digital technologies; business models; and SDGs. Therefore, the results obtained provide us with precise information that is scalable for different sectors. Thus, it is a unique study which, by integrating the PRISMA protocol and the AHP method, allows us to develop a summary of the state of art through a rigorous and scientific approach. From a practical point of view, several considerations emerged in terms of empirical evidence and main challenges as reported in the following sections.

\subsection{Synthesis to Move from Theory to Practice}

The analysis of the selected documents allows one to draw some considerations. Table 15 summarizes some empirical evidence and the main challenges that emerged from the analysis of scientific papers. It should be noted that the documents show that the characteristics of industry 4.0, that combine physical production with digital technology, are perfectly combined with the need to address development in a sustainable way. In addition, it emerged that companies belonging to sectors with a higher technological intensity innovate more on products and processes. A synthesis of the main evidence is shown below.

Table 15. Empirical evidence and main challenges.

\begin{tabular}{|c|c|c|}
\hline Authors & Empirical Evidence & Main Challenges \\
\hline $\begin{array}{l}\text { \#1. RESOLVE Framework } \\
\text { SC1.1 Regenerate }\end{array}$ & $\begin{array}{l}\text { Regenerate and proper waste disposal is } \\
\text { among the key issues analyzed by the } \\
\text { scientific community }\end{array}$ & $\begin{array}{l}\text { Lifecycle of products: from design, to production } \\
\text { methods, to their disposal. The aim is to ensure that } \\
\text { waste is avoided and that the resources used are kept } \\
\text { in the digital circular economy for as long as possible. } \\
\text { Legislative measures: favor interventions to establish a } \\
\text { new "right to reparation" for the consumer. }\end{array}$ \\
\hline $\begin{array}{l}\text { \#2. European } \\
\text { Eco-innovation Action Plan } \\
\text { SC2.5 GHG emission }\end{array}$ & $\begin{array}{l}\text { The scientific community agrees that the } \\
\text { starting point for the implementation of a } \\
\text { credible strategy to reduce GHG emission } \\
\text { must be quantified, following recognized } \\
\text { scientific principles, valid for everyone, } \\
\text { and obtaining a comparable and } \\
\text { repeatable result over time }\end{array}$ & $\begin{array}{l}\text { Interconnected databases: For climate protection, big } \\
\text { data and AI could make it possible to develop } \\
\text { predictive models capable of identifying the possible } \\
\text { effects of climate change and assessing the } \\
\text { effectiveness of law enforcement policies. } \\
\text { KPIs: Measuring emissions helps to disclose and } \\
\text { engage with "stakeholders", managing to } \\
\text { communicate transparently how the issue of climate } \\
\text { change is addressed and to demonstrate the } \\
\text { sustainability of one's business model over time. }\end{array}$ \\
\hline
\end{tabular}


Table 15. Cont.

\begin{tabular}{|c|c|c|}
\hline Authors & Empirical Evidence & Main Challenges \\
\hline $\begin{array}{l}\text { \#3. Digital Technologies } \\
\text { SC3.9 Big Data }\end{array}$ & $\begin{array}{l}\text { According to what emerges from the } \\
\text { scientific community, big data and data } \\
\text { analytics are enabling factors to } \\
\text { contribute to sustainable development }\end{array}$ & $\begin{array}{l}\text { Sustainable industry: Through Biga data, predictive } \\
\text { maintenance of machinery could be enabled, which } \\
\text { would prevent breakdowns, thus extending the life of } \\
\text { the machine and reducing waste of energy and } \\
\text { products. In addition, big data and data analytics are } \\
\text { enabling factors to contribute to energy efficiency. }\end{array}$ \\
\hline $\begin{array}{l}\text { \#4. Business models } \\
\text { SC4.1 Circular Supplies }\end{array}$ & $\begin{array}{c}\text { Researchers agreed that companies can } \\
\text { be active promoters of change, rather } \\
\text { than just undergoing it }\end{array}$ & $\begin{array}{l}\text { Territory: Investing in the national territory projects in } \\
\text { favor of the environment and the community that } \\
\text { welcomed them and the communities most in need. } \\
\text { Realities engaged in the reduction and recycling of the } \\
\text { resources necessary for production, as well as in the } \\
\text { efficiency of production processes. }\end{array}$ \\
\hline $\begin{array}{l}\text { \#5. SDGs } \\
\text { SC5.6 Climate Action } \\
\text { (SDG13) }\end{array}$ & $\begin{array}{l}\text { Academics around the world argue that } \\
\text { promoting effective action for climate } \\
\text { change requires not only climate data, } \\
\text { but also comprehensive information on } \\
\text { human behavior }\end{array}$ & $\begin{array}{l}\text { Climate Chain: Big data could help fight climate } \\
\text { change as it can offer us an answer on how humans } \\
\text { affect and are affected by the effects of climate change. } \\
\text { With this information it is possible to improve and } \\
\text { innovate on sustainability issues and in the ability we } \\
\text { have to recover and adapt. }\end{array}$ \\
\hline
\end{tabular}

\subsection{Challenges of Sustainability}

The challenges posed by digitalization and sustainability require an integrated approach to the legislative activity and to the coordination and cooperation of the action of all countries. In this sense, governments should promote new initiatives to regulate the artificial intelligence and big data sector, considered among the main technologies useful for the development of circular models, with particular attention to the ethical implications deriving from the use of algorithms. Another aspect to consider among the challenges for the circular economy is the development of global digital platforms as a tool for a virtuous use of resources capable of intercepting all of the stakeholders in the supply chain from a global "resource" market perspective, for the optimization of costs and waste at national and international levels, in compliance with recognized global standards as well as customized solutions, the result of applications of global scientific instruments. The real challenge is that everyone in their area (production, suppliers, customers) must contribute to the "system", generating value downstream and upstream to enable the factors for the transition and thus achieve sustainable sovereignty. Figure 15 summarizes global challenges in terms of enabling factors and the value chain.

In this context, it is clear that technological evolution goes hand in hand with sustainability. From a practical and operational point of view it has emerged that it is necessary to process and to analyze data in a few minutes that traditional computers would take tens of thousands of years to perform. The quantum supremacy achievable with the use of quantum computers looks promising in this scenario. The possible applications are innumerable: from predictive maintenance, which allows machines to repair themselves, to the development of smart cities, which aim to solve problems such as traffic and pollution thanks to advanced data analysis, up to the so-called internet of thing, i.e., objects capable of communicating with each other without human interaction (the technology underlying self-driving cars). The potential of quantum computers is so high that there are already experiments to build more performing batteries for cars, or to reduce greenhouse gases in the production of fertilizer. 


\section{Enabling factors for the sustainable and digital transition}
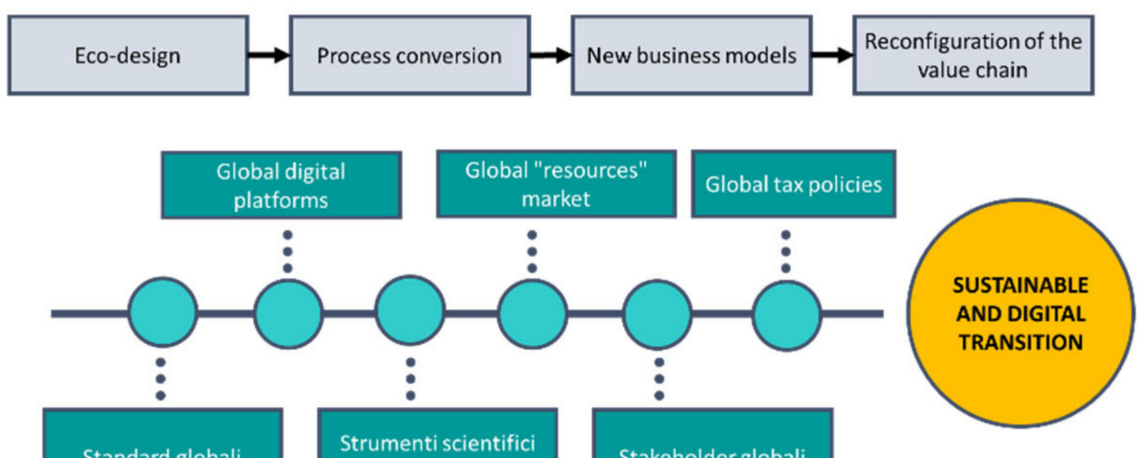

Standard globali

Strumenti scientifici globali

Stakeholder globali

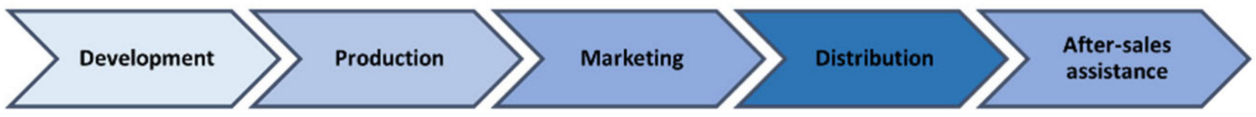

VALUE CHAIN

Figure 15. Global challenges in terms of enabling factors and the value chain (source: authors' elaboration).

\section{Conclusions}

\subsection{Concluding Remarks}

The digital transformation and the pandemic have contributed to raising awareness of the environmental crisis in the world, orienting managerial choices with a view to greater sustainability. The analysis conducted in this study shows that digital technologies represent a strategic component for the competitiveness of countries and for the evolution of production systems towards greater sustainability. Three fundamental principles emerged from the analysis:

- The sustainable use of renewable resources. This means that the rate of use should be less than the rate at which resources are able to regenerate;

- The sustainable use of non-renewable resources, i.e., their depletion must be compensated for by switching to renewable resources

- A sustainable emission rate for pollution and waste. According to this principle, the pace of emissions and waste production should not be faster than the rate at which natural systems can absorb, recycle or render them harmless.

Of course, there can be no ecological transition without a circular economy.

There are many opportunities that governments, companies and individuals themselves can make to foster sustainable development. However, to be effective, all actions must be performed globally. When it comes to environmental sustainability, no country is sovereign. Nowadays the awareness is that we live in a world with a global ecology, a global economy and global technologies. All countries are affected by the actions taken by those living in other parts of the world. In a globalized world, actions must be global to be effective.

\subsection{Limitations and Future Research Developments}

This research represents a preliminary study to investigate the role of digitalization to promote the circular economy. It is clear that all digital technologies are promising, but the real challenge lies in the ability to process large amounts of data to find the best solution. Thus, according this preliminary study, in our opinion, quantum technology is one of the keys of the future, which will allow us to tackle, through quantum computation, previously unsolvable problems for the development of circular economy models. Quantum computers are at the frontier of information technology and digital transformation with a view to 
sustainability (one of the technological revolutions destined to have a profound impact on our future). However, there will be an energy cost to pay for each quantum computing operation. Therefore, it is necessary to deepen the knowledge of the thermodynamic mechanisms that accompany quantum computation. In this way it will be possible to determine the energy cost behind carrying out a single operation. This represents an essential step in improving the performance of any machine designed for quantum computing. The aim of future research will be to investigate the evolution of supercomputer applications with a view to digital sustainability. In fact, the "generalist" quantum computer capable of tackling any type of problem has not yet been reached, but the line of development seems well designed.

Author Contributions: All authors contributed equally to this work. All authors have read and agreed to the published version of the manuscript.

Funding: This research received no external funding.

Institutional Review Board Statement: Not applicable.

Informed Consent Statement: Not applicable.

Conflicts of Interest: The authors declare no conflict of interest.

\section{References}

1. Bressanelli, G.; Perona, M.; Saccani, N. Challenges in supply chain redesign for the Circular Economy: A literature review and a multiple case study. Int. J. Prod. Res. 2018, 57, 7395-7422. [CrossRef]

2. Cioffi, R.; Travaglioni, M.; Piscitelli, G.; Petrillo, A.; Parmentola, A. Smart Manufacturing Systems and Applied Industrial Technologies for a Sustainable Industry: A Systematic Literature Review. Appl. Sci. 2020, 10, 2897. [CrossRef]

3. Zacharias, J. Addressing Global Climate Change with Big Data-Driven Urban Planning Policy. Int. J. E-Planning Res. 2021, 10, 1-16. [CrossRef]

4. Cetin, S.; De Wolf, C.; Bocken, N. Circular digital built environment: An emerging framework. Sustainability 2021, $13,6348$. [CrossRef]

5. Nikolaou, I.E.; Tsagarakis, K.P. An introduction to circular economy and sustainability: Some existing lessons and future di-rections. Sust. Product. Consumpt. 2021, 28, 600-609. [CrossRef]

6. Idrissi, N.; Zellou, A. A systematic literature review of sparsity issues in recommender systems. Soc. Netw. Anal. Min. 2020, 10, 15. [CrossRef]

7. Pieper, D.; Mathes, T.; Eikermann, M. Impact of choice of quality appraisal tool for systematic reviews in overviews. J. Evid. Based Med. 2014, 7, 72-78. [CrossRef] [PubMed]

8. Kitchenham, B. Procedures for Performing Systematic Reviews; Keele University Technical Report TR/SE-0401; Keele University: Keele, UK, 2004; ISSN 1353-7776.

9. Saaty, T.L. Modeling unstructured decision problems-The theory of analytical hierarchies. Math. Comput. Simul. 1978, 20, 147-158. [CrossRef]

10. Saaty, T.L. Applications of analytical hierarchies. Math. Comput. Simul. 1979, 21, 1-20. [CrossRef]

11. Ghisellini, P.; Cialani, C.; Ulgiati, S. A review on circular economy: The expected transition to a balanced interplay of environmental and economic systems. J. Clean. Prod. 2016, 114, 11-32. [CrossRef]

12. Contreras-Lisperguer, R.; Muñoz-Cerón, E.; Aguilera, J.; de la Casa, J. A set of principles for applying Circular Economy to the PV industry: Modeling a closed-loop material cycle system for crystalline photovoltaic panels. Sustain. Prod. Consum. 2021, 28, 164-179. [CrossRef]

13. Tapia, C.; Bianchi, M.; Pallaske, G.; Bassi, A.M. Towards a territorial definition of a circular economy: Exploring the role of territorial factors in closed-loop systems. Eur. Plan. Stud. 2021, 29, 1-20. [CrossRef]

14. Velvizhi, G.; Shanthakumar, S.; Das, B.; Pugazhendhi, A.; Priya, T.S.; Ashok, B.; Nanthagopal, K.; Vignesh, R.; Karthick, C. Biodegradable and non-biodegradable fraction of municipal solid waste for multifaceted applications through a closed loop integrated refinery platform: Paving a path towards circular economy. Sci. Total Environ. 2020, 731, 138049. [CrossRef] [PubMed]

15. Atabaki, M.S.; Mohammadi, M.; Naderi, B. New robust optimization models for closed-loop supply chain of durable products: Towards a circular economy. Comput. Ind. Eng. 2020, 146, 106520. [CrossRef]

16. Vanhamäki, S.; Virtanen, M.; Luste, S.; Manskinen, K. Transition towards a circular economy at a regional level: A case study on closing biological loops. Resour. Conserv. Recycl. 2020, 156, 104716. [CrossRef]

17. Lejarazu-Larrañaga, A.; Molina, S.; Ortiz, J.M.; Navarro, R.; García-Calvo, E. Circular economy in membrane technology: Using end-of-life reverse osmosis modules for preparation of recycled anion exchange membranes and validation in electro-dialysis. J. Memb. Sci. 2020, 593, 177423. [CrossRef] 
18. Sharma, R.; Andreasen, S.J.; Chamier, J.; Andersen, S.M. Pt/C Electrocatalyst Synthesis from Recycling of the Spent PEMFC Membrane Electrode Assembly: A Closed Loop Circular Economy. J. Electrochem. Soc. 2019, 166, F963-F970. [CrossRef]

19. Roy, M.; Linnanen, L.; Chakrabortty, S.; Pal, P. Developing a Closed-Loop Water Conservation System at Micro Level through Circular Economy Approach. Water Resour. Manag. 2019, 33, 4157-4170. [CrossRef]

20. Conforto, R. WSX-european waste services exchange, instrument to start the transition towards circular economy. Proc. Environ. Sci. Eng. Manag. 2019, 6, 61-71.

21. Sposato, P.; Preka, R.; Cappellaro, F.; Cutaia, L. Sharing economy and circular economy. How technology and collaborative consumption innovations boost closing the loop strategies. Environ. Eng. Manag. J. 2017, 16, 1797-1806. [CrossRef]

22. Meseguer-Sánchez, V.; Gálvez-Sánchez, F.J.; Molina-Moreno, V.; Wandosell-Fernández-De-Bobadilla, G. The Main Research Characteristics of the Development of the Concept of the Circular Economy Concept: A Global Analysis and the Future Agenda. Front. Environ. Sci. 2021, 9, 304. [CrossRef]

23. Vence, X.; Pereira, A. Eco-innovation and Circular Business Models as drivers for a circular economy. Cont. Admin 2018, 64, 1-7. [CrossRef]

24. Wang, N.; Lee, J.C.K.; Zhang, J.; Chen, H.; Li, H. Evaluation of Urban circular economy development: An empirical research of 40 cities in China. J. Clean. Prod. 2018, 180, 876-887. [CrossRef]

25. Lee, R.P.; Keller, F.; Meyer, B. A concept to support the transformation from a linear to circular carbon economy: Net zero emissions, resource efficiency and conservation through a coupling of the energy, chemical and waste management sectors. Clean Energy 2017, 1, 102-113. [CrossRef]

26. Strothman, P.; Sonnemann, G. Circular economy, resource efficiency, life cycle innovation: Same objectives, same impacts? Int. J. Life Cycle Assess. 2017, 22, 1327-1328. [CrossRef]

27. Lee, R.P.; Wolfersdorf, C.; Keller, F.; Meyer, B. Towards a closed carbon cycle and achieving a circular economy for carbo-naceous resources - net zero emissions, resource efficiency and resource conservation through coupling of the energy, chemical and recycling sectors. Oil Gas Eur. Mag. 2017, 43, 76-80.

28. Belmonte-Ureña, L.J.; Plaza-Úbeda, J.A.; Vazquez-Brust, D.; Yakovleva, N. Circular economy, degrowth and green growth as pathways for research on sustainable development goals: A global analysis and future agenda. Ecol. Econ. 2021, 185, 107050. [CrossRef]

29. Maldonado-Guzmán, G.; Garza-Reyes, J.A.; Pinzón-Castro, Y. Eco-innovation and the circular economy in the automotive industry. Benchmarking Int. J. 2020, 28, 621-635. [CrossRef]

30. Cainelli, G.; D'Amato, A.; Mazzanti, M. Resource efficient eco-innovations for a circular economy: Evidence from EU firms. Res. Policy 2019, 49, 103827. [CrossRef]

31. Novelli, V.; Geatti, P.; Ceccon, L.; Bettare, A. Eco-innovation in valcucine for a circular economy. Environ. Eng. Manag. J. 2018, 17, 2427-2436. [CrossRef]

32. Pagotto, M.; Halog, A. Towards a Circular Economy in Australian Agri-food Industry: An Application of Input-Output Oriented Approaches for Analyzing Resource Efficiency and Competitiveness Potential. J. Ind. Ecol. 2015, 20, 1176-1186. [CrossRef]

33. Sauvé, S.; Bernard, S.; Sloan, P. Environmental sciences, sustainable development and circular economy: Alternative concepts for trans-disciplinary research. Environ. Dev. 2016, 17, 48-56. [CrossRef]

34. Lu, Y. Circular economy development mode of coastal and marine areas in china and its evaluation index research-The example of qingdao. Int. J. Bioaut. 2014, 18, 121-130.

35. Johl, S.K.; Toha, M.A. The nexus between proactive eco-innovation and firm financial performance: A circular economy perspective. Sustainability 2021, 13, 6253. [CrossRef]

36. Kiefer, C.P.; del Río, P.; Carrillo-Hermosilla, J. On the contribution of eco-innovation features to a circular economy: A microlevel quantitative approach. Bus. Strategy Environ. 2021, 30, 1531-1547. [CrossRef]

37. Magazzino, C.; Mele, M.; Schneider, N.; Sarkodie, S.A. Waste generation, wealth and GHG emissions from the waste sector: Is denmark on the path towards circular economy? Sci. Total Environ. 2021, 755, 142510. [CrossRef] [PubMed]

38. Demirel, P.; Danisman, G.O. Eco-innovation and firm growth in the circular economy: Evidence from European small- and medium-sized enterprises. Bus. Strat. Environ. 2019, 28, 1608-1618. [CrossRef]

39. Laso, J.; García-Herrero, I.; Margallo, M.; Vázquez-Rowe, I.; Fullana, P.; Bala, A.; Aldaco, R. Finding an economic and environmental balance in value chains based on circular economy thinking: An eco-efficiency methodology applied to the fish canning industry. Res. Cons. Rec. 2018, 133, 428-437. [CrossRef]

40. Ncube, A.; Matsika, R.; Mangori, L.; Ulgiati, S. Moving towards resource efficiency and circular economy in the brick manufacturing sector in Zimbabwe. J. Clean. Prod. 2020, 281, 125238. [CrossRef]

41. Heath, G.A.; Silverman, T.J.; Kempe, M.; Deceglie, M.; Ravikumar, D.; Remo, T.; Cui, H.; Sinha, P.; Libby, C.; Shaw, S.; et al. Research and development priorities for silicon photovoltaic module recycling to support a circular economy. Nat. Energy 2020, 5, 502-510. [CrossRef]

42. Bartie, N.; Llamas, A.A.; Heibeck, M.; Fröhling, M.; Volkova, O.; Reuter, M. The simulation-based analysis of the resource efficiency of the circular economy-The enabling role of metallurgical infrastructure. Miner. Process. Extr. Metall. 2019, 129, 229-249. [CrossRef] 
43. Garcia-Muiña, F.E.; González-Sánchez, R.; Ferrari, A.M.; Volpi, L.; Pini, M.; Settembre-Blundo, D. Identifying the Equilibrium Point between Sustainability Goals and Circular Economy Practices in an Industry 4.0 Manufacturing Context Using Eco-Design. Soc. Sci. 2019, 8, 241. [CrossRef]

44. Durán-Romero, G.; López, A.M.; Beliaeva, T.; Ferasso, M.; Garonne, C.; Jones, P. Bridging the gap between circular economy and climate change mitigation policies through eco-innovations and Quintuple Helix Model. Technol. Forecast. Soc. Chang. 2020, 160, 120246. [CrossRef]

45. Ramkumar, S. Influence of Inter-Firm Network Relationships on Circular Economy Eco-Innovation Adoption. Sustainability 2020, 12, 7607. [CrossRef]

46. Matrapazi, V.; Zabaniotou, A. Experimental and feasibility study of spent coffee grounds upscaling via pyrolysis towards proposing an eco-social innovation circular economy solution. Sci. Total Environ. 2020, 718, 137316. [CrossRef] [PubMed]

47. Charles, R.G.; Douglas, P.; Baker, J.; Carnie, M.J.; Douglas, J.O.; Penney, D.; Watson, T.M. Platinized counter-electrodes for dye-sensitised solar cells from waste thermocouples: A case study for resource efficiency, industrial symbiosis and circular economy. J. Clean. Prod. 2018, 202, 1167-1178. [CrossRef]

48. Stankevičienè, J.; Nikanorova, M. Eco-innovation as a pillar for sustainable development of circular economy. Bus Theory Pract. 2020, 21, 531-544. [CrossRef]

49. de Jesus, A.; Antunes, P.; Santos, R.; Mendonça, S. Eco-innovation pathways to a circular economy: Envisioning priorities through a Delphi approach. J. Clean. Prod. 2019, 228, 1494-1513. [CrossRef]

50. de Jesus, A.; Antunes, P.; Santos, R.; Mendonça, S. Eco-innovation in the transition to a circular economy: An analytical literature review. J. Clean. Prod. 2018, 172, 2999-3018. [CrossRef]

51. de Jesus, A.; Mendonça, S. Lost in transition? drivers and barriers in the eco-innovation road to the circular economy. Ecol. Econ. 2018, 145, 75-89. [CrossRef]

52. Di Maio, F.; Rem, P.C.; Baldé, K.; Polder, M. Measuring resource efficiency and circular economy: A market value approach. Resour. Conserv. Recycl. 2017, 122, 163-171. [CrossRef]

53. Ma, S.; Hu, S.; Chen, D.; Zhu, B. A case study of a phosphorus chemical firm's application of resource efficiency and eco-efficiency in industrial metabolism under circular economy. J. Clean. Prod. 2015, 87, 839-849. [CrossRef]

54. Taiyang, Z.; Xianjin, H.; Lulu, L.; Chen, W. Comprehensive Assessment of Regional Circular Economy Development Based on Efficiency of Resource \& Environment: A Case Study of Jiangsu Province. Chin. J. Popul. Resour. Environ. 2006, 4, 54-64. [CrossRef]

55. Modgil, S.; Gupta, S.; Sivarajah, U.; Bhushan, B. Big data-enabled large-scale group decision making for circular economy: An emerging market context. Technol. Forecast. Soc. Chang. 2021, 166, 120607. [CrossRef]

56. Nobre, G.; Tavares, E. Assessing the Role of Big Data and the Internet of Things on the Transition to Circular Economy: Part II: An extension of the ReSOLVE framework proposal through a literature review. Johns. Matthey Technol. Rev. 2020, 64, 19-31. [CrossRef]

57. Nobre, G.C.; Tavares, E. Scientific literature analysis on big data and internet of things applications on circular economy: A bibliometric study. Scientometrics 2017, 111, 463-492. [CrossRef]

58. Górecki, J. Simulation-Based Positioning of Circular Economy Manager's Skills in Construction Projects. Symmetry 2019, 12, 50. [CrossRef]

59. Cui, Y.; Liu, W.; Rani, P.; Alrasheedi, M. Internet of things (IoT) adoption barriers for the circular economy using pythagorean fuzzy SWARA-CoCoSo decision-making approach in the manufacturing sector. Technol. Forecast. Soc. Chang. 2020, 171, 120951. [CrossRef]

60. Persis, D.J.; Venkatesh, V.; Sreedharan, V.R.; Shi, Y.; Sankaranarayanan, B. Modelling and analysing the impact of Circular Economy; Internet of Things and ethical business practices in the VUCA world: Evidence from the food processing industry. J. Clean. Prod. 2021, 301, 126871. [CrossRef]

61. Miaoudakis, A.; Fysarakis, K.; Petroulakis, N.; Alexaki, S.; Alexandirs, G.; Ioannidis, S.; Verikoukis, C. Pairing a circular economy and the 5G-enabled internet of things: Creating a class of? looping smart assets? IEEE Veh. Technol. Mag. 2020, 15, 20-31. [CrossRef]

62. Kazançoğlu, Y.; Sağnak, M.; Lafcı, Ç.; Luthra, S.; Kumar, A.; Taçoğlu, C. Big data-enabled solutions framework to overcoming the barriers to circular economy initiatives in healthcare sector. Int. J. Environ. Res. Public Health 2021, 18, 7513. [CrossRef]

63. Awan, U.; Shamim, S.; Khan, Z.; Zia, N.U.; Shariq, S.M.; Khan, M.N. Big data analytics capability and decision-making: The role of data-driven insight on circular economy performance. Technol. Forecast. Soc. Chang. 2021, 168, 120766. [CrossRef]

64. Kamble, S.S.; Belhadi, A.; Gunasekaran, A.; Ganapathy, L.; Verma, S. A large multi-group decision-making technique for prioritizing the big data-driven circular economy practices in the automobile component manufacturing industry. Technol. Forecast. Soc. Chang. 2021, 168, 120567. [CrossRef]

65. Bag, S.; Pretorius, J.H.C.; Gupta, S.; Dwivedi, Y.K. Role of institutional pressures and resources in the adoption of big data analytics powered artificial intelligence, sustainable manufacturing practices and circular economy capabilities. Technol. Forecast. Soc. Chang. 2021, 163, 120420. [CrossRef]

66. Del Giudice, M.; Chierici, R.; Mazzucchelli, A.; Fiano, F. Supply chain management in the era of circular economy: The moderating effect of big data. Int. J. Logist. Manag. 2020, 32, 337-356. [CrossRef] 
67. Waudby, H.; Zein, S.H. A circular economy approach for industrial scale biodiesel production from palm oil mill effluent using microwave heating: Design, simulation, techno-economic analysis and location comparison. Process. Saf. Environ. Prot. 2021, 148, 1006-1018. [CrossRef]

68. de la Torre, R.; Onggo, B.; Corlu, C.; Nogal, M.; Juan, A. The Role of Simulation and Serious Games in Teaching Concepts on Circular Economy and Sustainable Energy. Energies 2021, 14, 1138. [CrossRef]

69. Li, X.; Luo, F. Dynamic Simulation of Low-Carbon Competitiveness from the Perspective of Circular Economy. Complexity 2021, 2021, 6618940. [CrossRef]

70. Utrilla, P.N.; Górecki, J.; Maqueira, J.M. Simulation-based management of construction companies under the circular economy concept-case study. Buildings 2020, 10, 94. [CrossRef]

71. Llamas, A.A.; Bartie, N.J.; Heibeck, M.; Stelter, M.; Reuter, M.A. Simulation-Based Exergy Analysis of Large Circular Economy Systems: Zinc Production Coupled to CdTe Photovoltaic Module Life Cycle. J. Sustain. Metall. 2019, 6, 34-67. [CrossRef]

72. Sauerwein, M.; Doubrovski, E.; Balkenende, R.; Bakker, C. Exploring the potential of additive manufacturing for product design in a circular economy. J. Clean. Prod. 2019, 226, 1138-1149. [CrossRef]

73. Sauerwein, M.; Zlopasa, J.; Doubrovski, Z.; Bakker, C.; Balkenende, R. Reprintable paste-based materials for additive manufacturing in a circular economy. Sustainability 2020, 12, 8032. [CrossRef]

74. Giurco, D.; Littleboy, A.; Boyle, T.; Fyfe, J.; White, S. Circular Economy: Questions for Responsible Minerals, Additive Manufacturing and Recycling of Metals. Resources 2014, 3, 432-453. [CrossRef]

75. Wang, B.; Farooque, M.; Zhong, R.Y.; Zhang, A.; Liu, Y. Internet of things (IoT)-enabled accountability in source separation of household waste for a circular economy in china. J. Clean. Prod. 2021, 300, 126773. [CrossRef]

76. Magrini, C.; Nicolas, J.; Berg, H.; Bellini, A.; Paolini, E.; Vincenti, N.; Campadello, L.; Bonoli, A. Using Internet of Things and Distributed Ledger Technology for Digital Circular Economy Enablement: The Case of Electronic Equipment. Sustainability 2021, 13, 4982. [CrossRef]

77. Gupta, S.; Chen, H.; Hazen, B.T.; Kaur, S.; Gonzalez, E.D.R.S. Circular economy and big data analytics: A stakeholder perspective. Technol. Forecast. Soc. Chang. 2019, 144, 466-474. [CrossRef]

78. Wang, X. System simulation optimization of resource and environmental effects of circular economy. Nat. Environ. Pollut. Technol. 2019, 18, 1573-1578.

79. Charnley, F.; Tiwari, D.; Hutabarat, W.; Moreno, M.; Okorie, O.; Tiwari, A. Simulation to Enable a Data-Driven Circular Economy. Sustainability 2019, 11, 3379. [CrossRef]

80. van der Leer, J.; van Timmeren, A.; Wandl, A. Social-ecological-technical systems in urban planning for a circular economy: An opportunity for horizontal integration. Archit. Sci. Rev. 2018, 61, 298-304. [CrossRef]

81. Hatzivasilis, G.; Fysarakis, K.; Soultatos, O.; Askoxylakis, I.; Papaefstathiou, I.; Demetriou, G. The Industrial Internet of Things as an enabler for a Circular Economy Hy-LP: A novel IIoT protocol, evaluated on a wind park's SDN/NFV-enabled 5G industrial network. Comput. Commun. 2018, 119, 127-137. [CrossRef]

82. Lieder, M.; Asif, F.M.A.; Rashid, A. Towards Circular Economy implementation: An agent-based simulation approach for business model changes. Auton. Agents Multi-Agent Syst. 2017, 31, 1377-1402. [CrossRef]

83. Lieder, M.; Asif, F.M.A.; Rashid, A.; Mihelič, A.; Kotnik, S. Towards circular economy implementation in manufacturing systems using a multi-method simulation approach to link design and business strategy. Int. J. Adv. Manuf. Technol. 2017, 93, 1953-1970. [CrossRef]

84. Andreopoulou, Z. Internet of Things and food circular economy: A new tool for Sustainable Development Goals. Sustain. Dev. Goals 2017, 1, 43-49. [CrossRef]

85. Reuter, M.A. Digitalizing the circular economy: Circular economy engineering defined by the metallurgical internet of things. Metall. Mater. Trans. B 2016, 47, 3194-3220. [CrossRef]

86. Kumar, S.; Raut, R.D.; Nayal, K.; Kraus, S.; Yadav, V.S.; Narkhede, B.E. To identify industry 4.0 and circular economy adoption barriers in the agriculture supply chain by using ISM-ANP. J. Clean. Prod. 2021, 293, 126023. [CrossRef]

87. Nandi, S.; Hervani, A.A.; Helms, M.M. Circular Economy Business Models-Supply Chain Perspectives. IEEE Eng. Manag. Rev. 2020, 48, 193-201. [CrossRef]

88. Nandi, S.; Sarkis, J.; Hervani, A.; Helms, M. Do blockchain and circular economy practices improve post COVID-19 supply chains? A resource-based and resource dependence perspective. Ind. Manag. Data Syst. 2020, 121, 333-363. [CrossRef]

89. Kazancoglu, I.; Sagnak, M.; Mangla, S.K.; Kazancoglu, Y. Circular economy and the policy: A framework for improving the corporate environmental management in supply chains. Bus. Strat. Environ. 2020, 30, 590-608. [CrossRef]

90. Ciccullo, F.; Cagliano, R.; Bartezzaghi, G.; Perego, A. Implementing the circular economy paradigm in the agri-food supply chain: The role of food waste prevention technologies. Resour. Conserv. Recycl. 2020, 164, 105114. [CrossRef]

91. Safiullin, M.R.; Savelichev, M.V.; Elshin, L.A.; Moiseev, V.O. Increasing stability of economy through supply chain management and the circular economy. Int. J. Supply Chain Manag. 2020, 164, 721-725.

92. Alizadeh-Basban, N.; Taleizadeh, A.A. A hybrid circular economy - game theoretical approach in a dual-channel green supply chain considering sale's effort, delivery time, and hybrid remanufacturing. J. Clean. Prod. 2020, 250, 119521. [CrossRef]

93. Tacchini, M.; Burlini, I.; Bernardi, T.; De Risi, C.; Massi, A.; Guerrini, A.; Sacchetti, G. Chemical characterisation, antioxidant and antimicrobial screening for the revaluation of wine supply chain by-products oriented to circular economy. Plant Biosyst. - Int. J. Deal. Asp. Plant Biol. 2018, 153, 809-816. [CrossRef] 
94. Clark, N.; Trimingham, R.; Storer, I. Understanding the views of the UK food packaging supply chain in order to support a move to circular economy systems. Packag. Technol. Sci. 2019, 32, 577-591. [CrossRef]

95. Sharma, Y.K.; Mangla, S.K.; Patil, P.P.; Liu, S. When challenges impede the process: For circular economy-driven sustainability practices in food supply chain. Manag. Decis. 2019, 57, 995-1017. [CrossRef]

96. Kasulaitis, B.V.; Babbitt, C.W.; Krock, A.K. Dematerialization and the Circular Economy: Comparing Strategies to Reduce Material Impacts of the Consumer Electronic Product Ecosystem. J. Ind. Ecol. 2018, 23, 119-132. [CrossRef]

97. Douguet, J.-M.; Morlat, C.; Lanceleur, P.; Andriamasinoro, F. Subjective evaluation of aggregate supply scenarios in the ile-defrance region with a view to a circular economy: The ANR AGREGA research project. Int. J. Sustain. Dev. 2019, 22, 123-157. [CrossRef]

98. Daú, G.; Scavarda, A.; Scavarda, L.F.; Portugal, V.J.T. The Healthcare Sustainable Supply Chain 4.0: The Circular Economy Transition Conceptual Framework with the Corporate Social Responsibility Mirror. Sustainability 2019, 11, 3259. [CrossRef]

99. O'Connor, M.P.; Zimmerman, J.B.; Anastas, P.T.; Plata, D.L. A Strategy for Material Supply Chain Sustainability: Enabling a Circular Economy in the Electronics Industry through Green Engineering. ACS Sustain. Chem. Eng. 2016, 4, 5879-5888. [CrossRef]

100. Rashid, M.I.; Shahzad, K. Food waste recycling for compost production and its economic and environmental assessment as circular economy indicators of solid waste management. J. Clean. Prod. 2021, 317, 128467. [CrossRef]

101. Slorach, P.C.; Jeswani, H.K.; Cuéllar-Franca, R.; Azapagic, A. Environmental and economic implications of recovering resources from food waste in a circular economy. Sci. Total Environ. 2019, 693, 133516. [CrossRef]

102. Chen, C.-W. Clarifying rebound effects of the circular economy in the context of sustainable cities. Sustain. Cities Soc. 2020, 66, 102622. [CrossRef]

103. Llera-Sastresa, E.; Romeo, L.M.; Scarpellini, S.; Portillo-Tarragona, P. Methodology for Dimensioning the Socio-Economic Impact of Power-to-Gas Technologies in a Circular Economy Scenario. Appl. Sci. 2020, 10, 7907. [CrossRef]

104. Zhou, X.; Song, M.; Cui, L. Driving force for china's economic development under industry 4.0 and circular economy: Technological innovation or structural change? J. Clean. Prod. 2020, 271, 122680. [CrossRef]

105. Tian, X.; Richardson, R.E.; Tester, J.W.; Lozano, J.L.; You, F. Retrofitting Municipal Wastewater Treatment Facilities toward a Greener and Circular Economy by Virtue of Resource Recovery: Techno-Economic Analysis and Life Cycle Assessment. ACS Sustain. Chem. Eng. 2020, 8, 13823-13837. [CrossRef]

106. Kleines, L. Plasma technology as an ecological and economic opportunity in the circular economy for plastics. Spect. Eur. 2020, 32, $8-12$.

107. Micari, M.; Moser, M.; Cipollina, A.; Tamburini, A.; Micale, G.; Bertsch, V. Towards the implementation of circular economy in the water softening industry: A technical, economic and environmental analysis. J. Clean. Prod. 2020, 255, 120291. [CrossRef]

108. Mathur, N.; Singh, S.; Sutherland, J. Promoting a circular economy in the solar photovoltaic industry using life cycle symbiosis. Resour. Conserv. Recycl. 2019, 155, 104649. [CrossRef]

109. Lee, D.-H. Efficiency and economic benefit of dark-fermentative biohydrogen production in Asian circular economies: Evaluation using soft-link methodology with data envelopment analysis (DEA) and computable general equilibrium model (CGE). Int. J. Hydrog. Energy 2019, 45, 3688-3698. [CrossRef]

110. Chen, W.; Oldfield, T.L.; Katsantonis, D.; Kadoglidou, K.; Wood, R.; Holden, N.M. The socio-economic impacts of introducing circular economy into mediterranean rice production. J. Clean. Prod. 2019, 218, 273-283. [CrossRef]

111. Stadler, M.; Baganz, D.; Vermeulen, T.; Keesman, K. Circular economy and economic viability of aquaponic systems: Comparing urban, rural and peri-urban scenarios under Dutch conditions. Acta Hortic. 2017, 1176, 101-114. [CrossRef]

112. Roest, K.; Smeets, P.; van den Brand, T.; Zwertvaegher, A.; Cortial, H.; van Odijk, S.; Klaversma, E. Applicability of decentralized versus centralized drinking water production and wastewater treatment in an office park as example of a sustainble circular economy in amsterdam, the netherlands. Procedia Environ. Sci. Eng. Manag. 2016, 3, 139-148.

113. Richa, K.; Babbitt, C.W.; Gaustad, G. Eco-Efficiency Analysis of a Lithium-Ion Battery Waste Hierarchy Inspired by Circular Economy. J. Ind. Ecol. 2017, 21, 715-730. [CrossRef] 